\title{
Bioproducts From Euglena gracilis: Synthesis and Applications
}

\author{
Alexander Gissibl ${ }^{1,2}$, Angela Sun ${ }^{1,2}$, Andrew Care ${ }^{1}$, Helena Nevalainen ${ }^{1,2,3}$ and \\ Anwar Sunna ${ }^{1,2,3 *}$ \\ ${ }^{1}$ Department of Molecular Sciences, Macquarie University, Sydney, NSW, Australia, ${ }^{2}$ Australian Research Council Industrial \\ Transformation Training Centre for Molecular Technology in the Food Industry, Sydney, NSW, Australia, ${ }^{3}$ Biomolecular \\ Discovery and Design Research Centre, Macquarie University, Sydney, NSW, Australia
}

\section{OPEN ACCESS}

Edited by:

Susana Rodriguez-Couto, IKERBASQUE Basque Foundation for

Science, Spain

Reviewed by:

Philip Thomas Pienkos,

National Renewable Energy Laboratory (DOE), United States

Rafael Moreno-Sánchez, Instituto Nacional de Cardiologia

Ignacio Chavez, Mexico

${ }^{*}$ Correspondence: Anwar Sunna anwar.sunna@mq.edu.au

Specialty section:

This article was submitted to Industrial Biotechnology,

a section of the journal Frontiers in Bioengineering and Biotechnology

Received: 28 December 2018 Accepted: 29 April 2019 Published: 15 May 2019

Citation:

Gissibl A, Sun A, Care A, Nevalainen $H$ and Sunna A (2019) Bioproducts From Euglena gracilis: Synthesis and Applications. Front. Bioeng. Biotechnol. 7:108. doi: 10.3389/fbioe.2019.00108
In recent years, the versatile phototrophic protist Euglena gracilis has emerged as an interesting candidate for application-driven research and commercialisation, as it is an excellent source of dietary protein, pro(vitamins), lipids, and the $\beta$-1,3-glucan paramylon only found in euglenoids. From these, paramylon is already marketed as an immunostimulatory agent in nutraceuticals. Bioproducts from E. gracilis can be produced under various cultivation conditions discussed in this review, and their yields are relatively high when compared with those achieved in microalgal systems. Future challenges include achieving the economy of large-scale cultivation. Recent insights into the complex metabolism of $E$. gracilis have highlighted unique metabolic pathways, which could provide new leads for product enhancement by genetic modification of the organism. Also, development of molecular tools for strain improvement are emerging rapidly, making E. gracilis a noteworthy challenger for microalgae such as Chlorella spp. and their products currently on the market.

Keywords: Euglena gracilis, biosynthesis, dietary protein, vitamins, polyunsaturated fatty acids, wax esters, paramylon, large-scale cultivation

\section{BACKGROUND}

The unicellular phototrophic protist E. gracilis is ubiquitous in most freshwater biotopes. It is capable of photoautotrophic (using sunlight), heterotrophic (using an external carbon source), and mixotropic (combining both modes) growth (Rodríguez-Zavala et al., 2010; Šantek et al., 2010; Buetow, 2011). Commercially relevant bioproducts synthesised by E. gracilis feature protein containing essential amino acids, pro(vitamins), lipids, and the $\beta$-1,3-glucan paramylon (Takeyama et al., 1997; Rodríguez-Zavala et al., 2010; Pollak et al., 2012).

Euglena gracilis has a natural ability to tolerate a number of external stresses, including acidic growth conditions and ionising radiation, and has been shown to be capable of heavy metal sequestration (Yamane et al., 2001; Hayashi et al., 2004; García-García et al., 2018). This physical endurance and metabolic adaptability may be harnessed for bioremediation of polluted water containing elevated levels of nitrogen, phosphates, organic carbon, $\mathrm{Cd}^{2+}, \mathrm{Cr}^{3+}, \mathrm{Hg}^{2+} \mathrm{Cr}^{6+}, \mathrm{Pb}^{2+}$, uranium, and/or $\mathrm{Zn}^{2+}$ (Mahapatra et al., 2013; García-García et al., 2014).

Euglena gracilis can accumulate large amounts of the reserve polysaccharide paramylon, a $\beta-1,3-$ glucan, which can constitute over $80 \%$ (w/w) of the dry weight (DW, biomass dried to a constant weight without oxidation) (Barsanti et al., 2001; Sun et al., 2018). Paramylon is uniquely produced by euglenoids, deposited as granules in the cytosol, and readily degraded and utilised as a carbon source under carbon starvation (Malkoff and Buetow, 1964; Kiss et al., 1986; Barsanti et al., 2001; Monfils et al., 2011). Paramylon and other $\beta$-1,3-glucans are of special interest because of their 
reported immunostimulatory and antimicrobial bioactivities (Kiss et al., 1986; Barsanti et al., 2001; Russo et al., 2017; Gissibl et al., 2018). Additionally, $\beta$-1,3-glucans have been shown to lower cholesterol levels and exhibit antidiabetic, antihypoglycemic and hepatoprotective activities; they have also been used for the treatment of colorectal and gastric cancers (Ooi and Liu, 2000; Kataoka et al., 2009; Barsanti et al., 2011).

Improvement of the performance of $E$. gracilis has mainly relied on developing cultivation conditions to favour the synthesis of the compound of interest, followed by scale-up of the cultivation volume, because of a general lack of genetic information on the metabolic pathways leading to the various bioproducts (O'Neill et al., 2015a; Wang et al., 2018). While a draft genome assembly and initial features of the genome have been made available, a complete annotated genome sequence is not on hand as yet (O'Neill et al., 2015a; Ebenezer et al., 2017). The large size and complexity of the E. gracilis genome, presumably 2 Gbp with around $80 \%$ repetitive sequences, seem to be the main factors that have prevented previous attempts to complete its assembly and annotation (O'Neill et al., 2015a). In the absence of complete genetic information, transcriptomic and proteomic studies have provided valuable insights into the complex metabolic pathways of E. gracilis and their regulation under different growth conditions (O’Neill et al., 2015b; Yoshida et al., 2016; Hasan et al., 2017).

There are a few isolated reports on genetic manipulation of E. gracilis. For example, transformation of E. gracilis chloroplasts with the gene coding for a cyanobacterial fructose1,6-/sedoheptulose-1,7-bisphosphatase has been achieved by biolistic bombardment (Doetsch et al., 2001; Ogawa et al., 2015). Gene knockdown via RNA interference (RNAi) has led to the identification of the role of photoactivated adenylyl cyclase in phototaxis and the finding that glucan synthase-like 2 is essential for paramylon synthesis (Ntefidou et al., 2003; Tanaka et al., 2017). Recently, Khatiwada et al. reported a nuclear transformation platform facilitating further molecular genetic studies and the metabolic modification of E. gracilis (Khatiwada et al., 2019). The study showed that Agrobacterium-mediated transformation was superior to electroporation and biolistic bombardment, resulting in stable E. gracilis transformants. A number of E. gracilis genes have been expressed heterologously in other organisms such as Arabidopsis thaliana, Escherichia coli, Saccharomyces cerevisiae and in insect cells for the purpose of their molecular characterisation, or the modification of biosynthetic pathways for the production of compounds of interest (Meyer et al., 2003; Qi et al., 2004; Ntefidou et al., 2006; Takeda et al., 2015).

There is a growing interest in the commercial exploitation of E. gracilis based on the organism's versatility, resilience and capability to synthesise a broad and unique range of bioproducts (Suzuki, 2017). Here we present an overview of valuable bioproducts (e.g., dietary protein, provitamin A, vitamin C, vitamin E, lipids, and paramylon) and their cultivation condition-dependent synthesis in E. gracilis with special consideration to their industrial relevance and future development (Figure 1).

\section{NUTRITIONAL VALUE OF E. GRACILIS \\ Dietary Protein}

There is a growing global demand for dietary protein with a high nutritional value due to the increasing human population in concurrence with socio-economic changes (Henchion et al., 2017). Microalgae can accumulate large quantities of proteins intracellularly and therefore represent an attractive alternative to more traditional sources of dietary protein like meat and fish (Henchion et al., 2017; Ritala et al., 2017). In this context, E. gracilis has been shown to produce protein containing all 20 proteinogenic amino acids (Isegawa et al., 1993; RodríguezZavala et al., 2010; Hasan et al., 2017). Importantly, animal and in vitro studies have shown an excellent digestibility of protein derived from E. gracilis biomass (Hosotani and Kitaoka, 1977).

The mode of cultivation has a major impact on the total protein content of E. gracilis (Table 1), especially when comparing photoautotrophic (PT), heterotrophic (HT), and mixotrophic (MT) growth conditions. For example, HT growth in a medium supplemented with external nitrogen (ammonium) has resulted in the production of cell mass with a protein content of close to $0.7 \mathrm{~g} / \mathrm{g} \mathrm{DW}$, whereas PT cultivation maximally yields $0.5 \mathrm{~g} / \mathrm{g}$ DW (Chae et al., 2006; RodríguezZavala et al., 2010). Regardless of the cultivation mode, dried E. gracilis cell mass would be competitive in terms of its protein content with fresh high-protein animal products such as beef, chicken or fish, of which the protein content usually does not exceed $0.4 \mathrm{~g} / \mathrm{g}$ after cooking (Table 1). Therefore, protein sourced from E. gracilis could provide an alternative to supplement a vegetarian diet (US Department of Agriculture., 2018). The protein content of E. gracilis is on a par with popular microalgal food supplements such as those sourced from Chlorella spp. (Table 1) (de Oliveira et al., 1999; Tokuşoglu and Ünal, 2003; Ramazanov and Ramazanov, 2006; Rodríguez-Zavala et al., 2010).

Initial transcriptomic studies indicated that amino acid synthesis pathways in E. gracilis were similar to those used by plants and bacteria (O’Neill et al., 2015b). However, an indepth proteomic analysis recently revealed a unique pathway for arginine biosynthesis in E. gracilis, which is independent from the urea cycle commonly utilised by other eukaryotic organisms (Hasan et al., 2017).

\section{(Pro)Vitamin A, C, and E}

Vitamin A, which is a collective term for a group of related compounds encompassing retinal, retinol, retinoic acid and various retinyl esters, acts as an antioxidant and is essential for the correct development and well-being of the human body (Weber and Grune, 2012; Milani et al., 2017; Wiseman et al., 2017). Deficiencies of this micronutrient can have severe health effects such as blindness in infants or an increased mortality rate during infections (Weber and Grune, 2012; Wiseman et al., 2017). Vitamin A is found only in animal products (e.g., fish and dairy) and its global human intake is currently supplemented to a large degree with plant-derived provitamin A ( $\beta$-carotene). However, the metabolic conversion efficiency of $\beta$-carotene to vitamin A, generally considered to be $12: 1$, is dependent on 


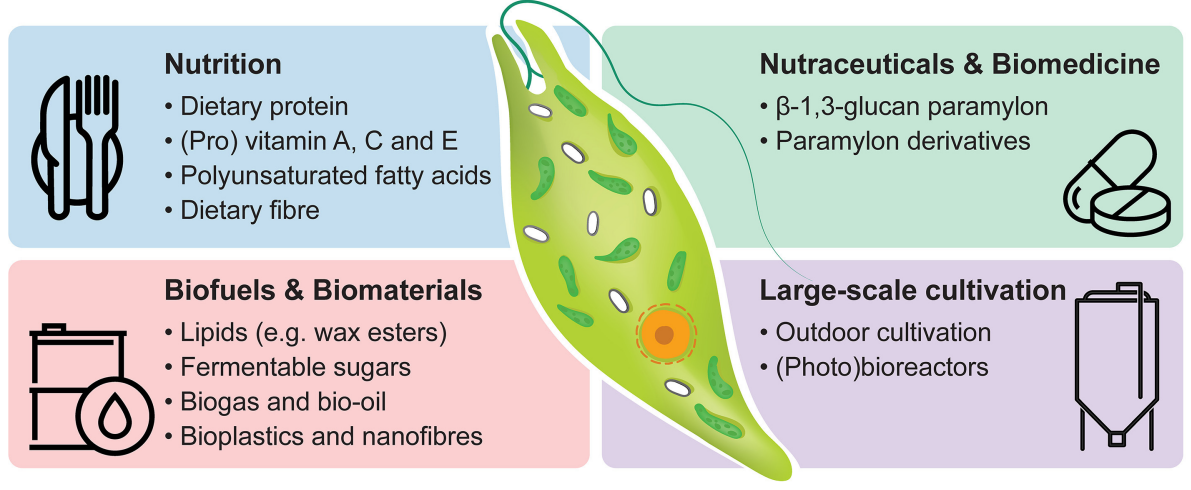

FIGURE 1 | Industrial potential of Euglena gracilis. Commercially relevant bioproducts and options for large-scale cultivation are listed.

several factors (e.g., bioavailability) and always needs to be taken into account in a dietary context (Weber and Grune, 2012).

Like other photosynthetic microorganisms, E. gracilis produces $\beta$-carotene as a protective pigment to ward off photooxidative damage to chloroplasts. Consequently, $\beta$-carotene titres per g DW are highest under PT cultivation conditions (Table 1). However, DW titres of E. gracilis under PT conditions are significantly lower than those obtained with MT/HT growth (Table 1) (Takeyama et al., 1997; Hasan et al., 2017). To circumvent this issue, a fed-batch two-step cultivation method with a transition from MT to PT growth conditions has been developed and shown to increase the $\beta$-carotene titre per $\mathrm{L}$ culture more than 6-fold (Table 1) (Takeyama et al., 1997).

The $\beta$-carotene content of E. gracilis cell mass grown in this two-step cultivation process or under PT conditions (3.4 or $3.5 \mathrm{mg} / \mathrm{g} \mathrm{DW}$, respectively) is exceptional, even in comparison with vegetables known to be high in $\beta$-carotene (Table 1). For example, dried E. gracilis cell mass contains up to 10 -fold more $\beta$-carotene than dehydrated carrots (Table 1) (Takeyama et al., 1997; Weber and Grune, 2012; US Department of Agriculture., 2018). The recommended daily intake of vitamin A varies between countries, but is generally around $800 \mu \mathrm{g}$ for an adult, which is equivalent to approximately $9.6 \mathrm{mg}$ of the provitamin $\beta$-carotene or around $3 \mathrm{~g}$ of dehydrated E. gracilis cell mass with maximised $\beta$-carotene content (Takeyama et al., 1997; Weber and Grune, 2012). Therefore, E. gracilis cell mass can be considered an excellent vitamin A supplement and could improve a vitamin A-poor diet.

A better understanding of the E. gracilis pathway for $\beta$-carotene biosynthesis (Figure 2A) could hold the key to further improve the yields. Two alternative metabolic routes to $\beta$-carotene have been identified biochemically or via transcriptomics in E. gracilis: the methylerythritol phosphate and the mevalonate pathway (Disch et al., 1998; Kim et al., 2004; O’Neill et al., 2015b). Many of the last enzymatic steps between the central intermediate isopentenyl pyrophosphate and the end product remain to be elucidated, as only the enzymes geranylgeranyl pyrophosphate synthase and phytoene synthase (see Figure 2A) have been verified by complementing the partially deleted carotenoid biosynthetic pathway of Pantoea ananatis expressed in E. coli with E. gracilis enzymes (Kato et al., 2016). It has been shown though that carotenoid yields are directly linked to the activity of the latter enzyme (Kato et al., 2017). However, more research is needed to determine if these enzymes could be a feasible target for strain improvement to increase $\beta$-carotene yields.

Vitamin C (ascorbate) is critical for human health as it acts as an antioxidant and co-factor for several enzymes involved in essential biosynthesis pathways (Grosso et al., 2013; Aghajanian et al., 2015). The unique ascorbate synthesis pathway from E. gracilis (Figure 2B) has been elucidated using radiotracer experiments, as well as transcriptomic and proteomic studies (Ishikawa and Shigeoka, 2008; O’Neill et al., 2015b; Hasan et al., 2017). At present, only two enzymes of this pathway, the D-galacturonate reductase and aldonolactonase, have been biochemically characterised in vitro. In an RNAi experiment, the latter enzyme has been shown to be essential for the ascorbatedependent growth of the organism. Although these enzymes reportedly play a key role in E. gracilis ascorbate synthesis, a comparison between radiotracer studies indicated that the pathway flux is controlled by the epimerisation reaction catalysed by the uridine diphosphate D-glucuronate 4-epimerase (Shigeoka et al., 1979; Ishikawa et al., 2006; Ishikawa and Shigeoka, 2008). However, further studies are needed to confirm this proposed regulatory role.

PT cultivation induces the synthesis of ascorbate in E. gracilis as a mechanism to cope with reactive oxygen species (ROS) produced during photosynthesis (ROS scavenging). In addition, the enzyme ascorbate peroxidase reduces excess hydrogen peroxide to water by oxidation of ascorbate (Shigeoka et al., 1980; Ishikawa et al., 2010; Hasan et al., 2017). The typical ascorbate titre of a PT-cultivated E. gracilis is around $4 \mathrm{mg} / \mathrm{g}$ DW or $8 \mathrm{mg} / \mathrm{L}$ culture, whereas it is negligible for E. gracilis cultivated under HT conditions (Shigeoka et al., 1980; Hasan et al., 2017). The overall titre can be increased to $86.5 \mathrm{mg} / \mathrm{L}$ culture by the fed-batch two-step (MT to PT) cultivation method discussed above (Takeyama et al., 1997). It should be noted that ascorbate production by $E$. gracilis has not attracted much 


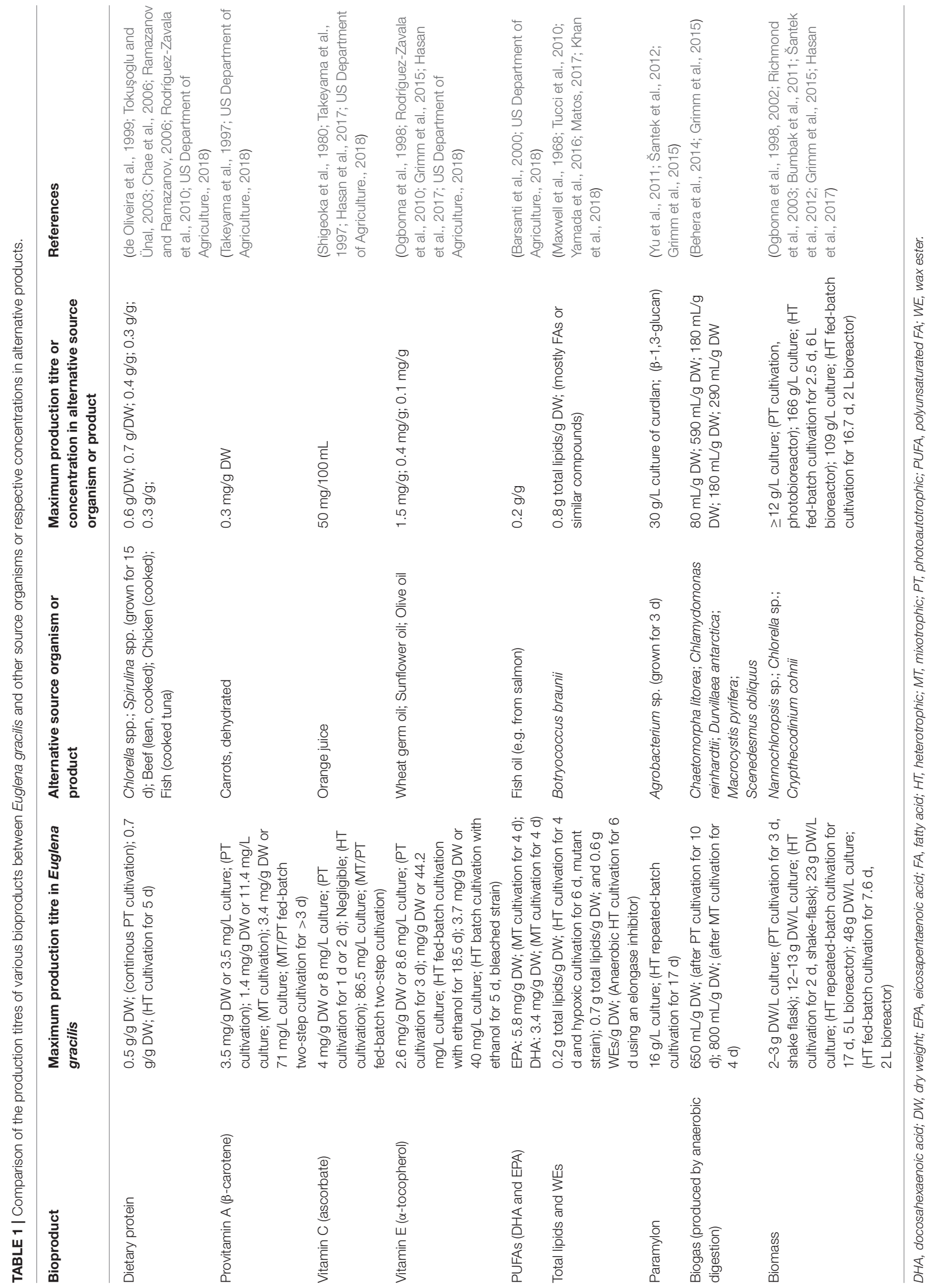



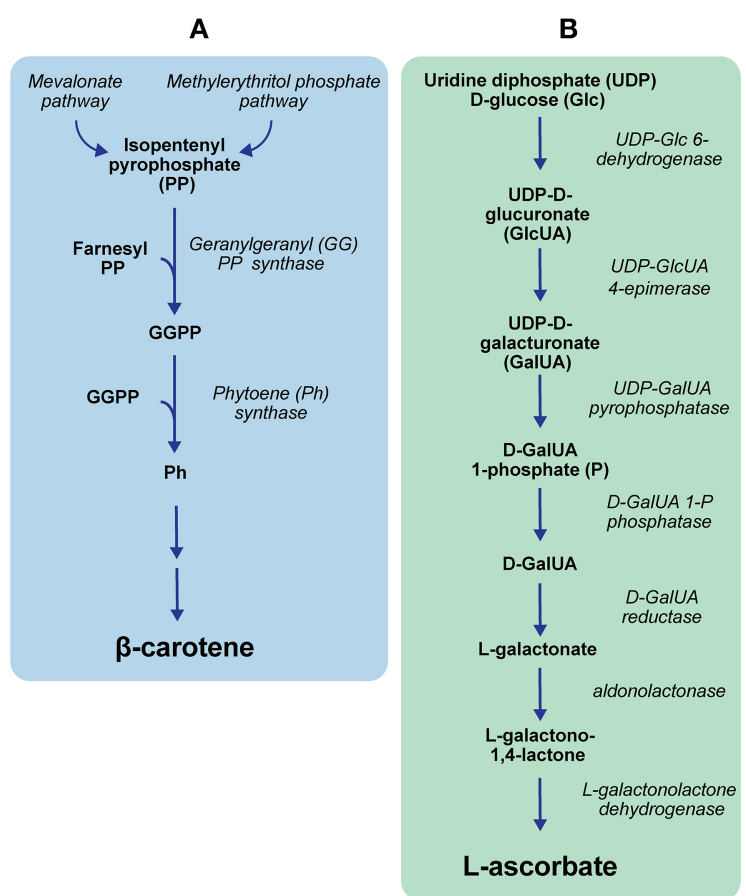
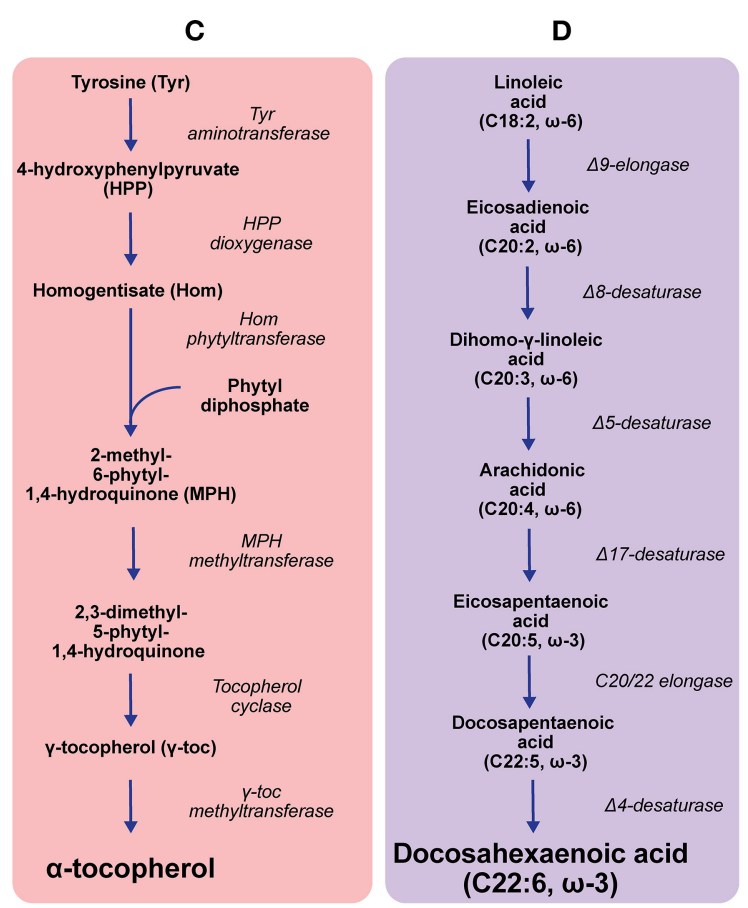

FIGURE 2 | Euglena gracilis biosynthesis pathways of $\beta$-carotene (A), ascorbate (B), $\alpha$-tocopherol (C), and polyunsaturated fatty acids (D) (Shigeoka et al., 1992 ; Kim et al., 2004; Ishikawa et al., 2006; Ishikawa and Shigeoka, 2008; Lohr et al., 2012; Pollak et al., 2012; O’Neill et al., 2015b; Kato et al., 2016; Hasan et al., 2017). Only central enzymes/substrates/intermediates/products are shown.

attention, probably because consumption of just 100 to $200 \mathrm{~mL}$ of juice from citrus fruits like oranges (Table 1) is enough to fulfil the daily recommended intake of adults (75 and $90 \mathrm{mg}$ for females and males, respectively) (Grosso et al., 2013; US Department of Agriculture., 2018). Nevertheless, ascorbate and other bioproducts like vitamin $\mathrm{E}$ remain an important component of commercially available food supplements based on E. gracilis cell mass (Barsanti and Gualtieri, 2018).

Both $\alpha$ - and $\gamma$-tocopherol are, amongst $\beta$ - and $\delta$-, the major forms of dietary vitamin E. The $\alpha$-form is one of the most abundant lipophilic antioxidants and considered more important for mammalian physiology. Adverse health effects, including neurological damage or anaemia, are associated with $\alpha$-tocopherol deficiency (Niki and Traber, 2012). However, $\gamma$ tocopherol is the main dietary form in countries where consumed vegetable oils derive predominantly from soy and corn (e.g., in the USA), leading to an insufficient intake of $\alpha$-tocopherol in these regions (Jiang et al., 2001; Rigotti, 2007; Traber, 2014).

Euglena gracilis has a plant-like $\alpha$-tocopherol pathway, which has been confirmed by transcriptomic and proteomic studies. However, unlike higher plants, E. gracilis produces almost exclusively the $\alpha$-form of tocopherol (Shigeoka et al., 1986; O’Neill et al., 2015b; Fritsche et al., 2017; Hasan et al., 2017). A key enzyme in its $\alpha$-tocopherol synthesis pathway (Figure 2C) is $\gamma$-tocopherol methyltransferase (Shigeoka et al., 1986, 1992). This enzyme converts $\gamma$-tocopherol to $\alpha$-tocopherol using $S$ adenosyl methionine (SAM) as the methyl group donor and also shows promiscuity towards $\beta$ - and $\delta$-tocopherol (Shigeoka et al., 1992). Compared to some $\gamma$-tocopherol methyltransferases from plants, the E. gracilis enzyme has a high $\mathrm{K}_{\mathrm{M}}$ value $(50 \mu \mathrm{M}$ for SAM) and low specific activity $(251 \mathrm{nmol} / \mathrm{h}$ per $\mathrm{mg}$ protein for $\gamma$-tocopherol) (Shigeoka et al., 1992; Koch et al., 2003). Yet, it is assumed that the conversion of $\gamma$-tocopherol to $\alpha$ tocopherol is the rate-limiting step in the pathway of plants (Fritsche et al., 2017). Identifying what control mechanisms make E. gracilis so efficient in producing $\alpha$-tocopherol could lead to strategies for the modification of higher plants to increase their $\alpha$-tocopherol yields.

There are several factors influencing $\alpha$-tocopherol levels in $E$. gracilis, for example, cultivation under light conditions or the addition of ethanol to the medium have been shown to increase $\alpha$-tocopherol production (Table 1) (Kusmic et al., 1998; Fujita et al., 2008). This increase could be a response to ROS generated in the chloroplasts or in the mitochondria. Yet, the influence of light was shown to be independent of the presence of chlorophyll, suggesting that mitochondria may be primarily responsible for the regulation of $\alpha$-tocopherol synthesis (Kusmic et al., 1998; Ogbonna et al., 1998; Fujita et al., 2008; Hasan et al., 2017). Long incubation times and supplementation of the medium with a carbon source (MT cultivation) have been shown to maximise the overall $\alpha$-tocopherol yield due to an increase in the amount of cell mass. However, it has also been shown that $\alpha$-tocopherol titres per g DW decrease under MT/HT cultivation (without ethanol) over time (Grimm et al., 2015; Hasan et al., 2017). These 
factors need to be taken into account when determining the most favourable time of harvest.

The technical set-up of a cultivation also plays an important role in $\alpha$-tocopherol production, for example, hydrodynamic stress caused by fast stirring with baffled plates in a bioreactor cultivation has been shown to have a detrimental effect on the final yields of $\alpha$-tocopherol during HT cultivation (Ogbonna et al., 1998). So far, the highest reported total $\alpha$-tocopherol titres of $44.2 \mathrm{mg} / \mathrm{L}$ culture or $1.1 \mathrm{mg} / \mathrm{g} \mathrm{DW}$ were achieved with E. gracilis in HT fed-batch cultivation after $455 \mathrm{~h}$ in a medium containing ethanol as a carbon source (Ogbonna et al., 1998). Comparable levels of $40 \mathrm{mg} / \mathrm{L}$ culture or $3.7 \mathrm{mg} / \mathrm{g} \mathrm{DW}$ were reached after a relatively short incubation time of $120 \mathrm{~h}$ using a bleached strain in HT batch cultivation with a medium supplemented with ethanol, glutamate and malate (RodríguezZavala et al., 2010). In contrast, some vegetable oils (e.g., olive, sunflower, and wheat germ oil) are marketed as good sources of daily vitamin $\mathrm{E}$ intake, but only have maximum $\alpha$-tocopherol contents of $1.5 \mathrm{mg} / \mathrm{g}$ (Table 1), which further emphasises the commercial potential of $E$. gracilis as a viable candidate for industrial $\alpha$-tocopherol production (Psomiadou et al., 2000; US Department of Agriculture., 2018). To the best of our knowledge, there are currently no reports of a commercial $\alpha$-tocopherol production using E. gracilis.

\section{Polyunsaturated Fatty Acids (PUFAs)}

PUFAs of the $\omega-3$ or $\omega-6$ series are defined by their first double bond at the position between the third and fourth or sixth and seventh carbon counted from the methyl end, respectively, and are considered essential for mammalian nutrition. In the Western world, major health conditions like cardiovascular and neurological diseases have been linked directly to a lack of longchain $\omega$-3 PUFAs, especially eicosapentaenoic acid (EPA) and docosahexaenoic acid (DHA), in the dietary intake (Deckelbaum and Torrejon, 2012; Innis, 2014). Euglena gracilis has a pathway for the synthesis of EPA and subsequently DHA (Figure 2D), and the enzymes within this pathway have been characterised biochemically. The proposed activity of $\Delta 17$-desaturase and C20/22 elongase (see Figure 2D) has been verified in E. gracilis cell extract only, whereas genes encoding the other enzymes (see Figure 2D) have been expressed heterologously (Wallis and Browse, 1999; Meyer et al., 2003; Qi et al., 2004; Damude et al., 2010; Pollak et al., 2012; Zhu et al., 2014).

Reported EPA and DHA titres in E. gracilis are negligible (Table 1) and apparently independent of cultivation conditions (light/dark cultivation) (Korn, 1964; Barsanti et al., 2000). These low titres could represent a good target for improvement by genetic engineering or non-recombinant metabolic engineering techniques based on the selection of improved phenotypes after the application of a selective pressure such as adaptive laboratory evolution (Portnoy et al., 2011; Dragosits and Mattanovich, 2013; Khatiwada et al., 2019). In an alternative approach, genes encoding single enzymes of the E. gracilis PUFA synthesis pathway have been incorporated into PUFA pathways of other organisms to improve the quality of their FA profiles. For example, the $\Delta 8$-desaturase from the E. gracilis pathway (see Figure 2D) has been incorporated into $A$. thaliana along with enzymes from other organisms for the production of EPA. In another report, the $\Delta 4$-desaturase from $E$. gracilis (see Figure 2D) was expressed together with the $\Delta 15$-desaturase from Caenorhabditis elegans in mammalian cells, resulting in a shift of the intracellular FA profile towards more valuable EPA and DHA (Qi et al., 2004; Zhu et al., 2014).

\section{BIOFUELS AND BIOACTIVE COMPOUNDS}

\section{Wax Esters (WEs) and Other Lipids}

Microalgae have been proposed as a source of feedstock for the production of biofuels such as biodiesel because of the high amounts of lipids, mostly FAs and WE, accumulated during the growth of some microalgal species (Matos, 2017). WEs can be used directly as biodiesel, whereas FAs must be processed first by esterification with an alcohol to yield WEs. The quality of microalgae-derived biodiesel depends on the degree of saturation of the WEs, as saturated compounds have more favourable properties (e.g., higher cetane number) (Ramos et al., 2009; Andreani and Rocha, 2012). Furthermore, there is a preference for the use of short- or medium-chain esters over long-chain esters in the industrial production of diesel and kerosene because shorter esters provide better cold flow properties and oxidative stability (Maurice et al., 2001). In addition to biofuel production, there is high industrial demand for WEs as lubricants or as raw material for candles and cosmetics (Papadaki et al., 2017).

In E. gracilis, WE synthesis serves as an electron sink for ATP production through glycolysis during anaerobiosis. Accordingly, the cells synthesise FAs, fatty alcohols (FAlcs) and ultimately WEs in larger quantities from paramylon under oxygen-limiting conditions (Inui et al., 1984; Tucci et al., 2010; Furuhashi et al., 2015; Yoshida et al., 2016). The central enzymatic steps of the pathway for WE formation in E. gracilis are catalysed by fatty acyl-CoA reductase (EgFAR) and wax synthase (EgWS). Wax ester synthase/diacylglycerol acyltransferase (EgWSD) isozymes have been shown to fulfil a role similar to that of EgWS. For example, RNAi-mediated silencing of EgWSD isoenzymes resulted in reduced wax ester production in E. gracilis (Teerawanichpan and Qiu, 2010; Tomiyama et al., 2017).

Heterologous expression of EgFAR together with EgWS in the industrially relevant organism $S$. cerevisiae has been shown to produce WEs of medium chain lengths from supplemented FAs. These findings highlight the potential of E. gracilis enzymes for the microbial production of biofuels (Teerawanichpan and Qiu, 2010; Tomiyama et al., 2017; Nandy and Srivastava, 2018).

The majority of the E. gracilis-derived lipids (WEs and FAs) are suitable for biodiesel production because they are saturated or have a low degree of unsaturation (Rosenberg, 1963; Tucci et al., 2010; Furuhashi et al., 2015). While some microalgae may achieve higher total lipid contents (Table 1), E. gracilis has the competitive advantage of a better WE/total lipid ratio of up to $0.8 \mathrm{~g} / \mathrm{g}$, as lipids produced by most microalgae are typically FAs (Maxwell et al., 1968; Tucci et al., 2010; Matos, 2017; Khan et al., 2018). Moreover, E. gracilis WEs are more suited for catalytic cracking for the production of fuel as the reaction is faster with less formation of unwanted poorly combustible polyaromatic compounds (Shimada et al., 2018). Enzymes of 
the FA biosynthesis pathway in E. gracilis have been shown to be crucial for the quality of WE derived from E. gracilis. For example, silencing of the genes coding for the E. gracilis 3-ketoacyl-CoA thiolase (EgKAT) isozymes EgKAT 1, EgKAT 2 and EgKAT 3 via RNAi lead to an increased production of short-chain WEs, and an artificial biodiesel inferred from the lipid composition before and after gene silencing indicated an improvement of cold flow properties (Nakazawa et al., 2015).

The lipid yield and the ratio of FAs/FAlcs to WEs have been shown to be strongly dependent on the cultivation conditions and the E. gracilis strain used (Tucci et al., 2010). As yet, a maximum total lipid and WE titre of $\sim 0.7$ and $0.6 \mathrm{~g} / \mathrm{g} \mathrm{DW}$, respectively, was reached during anaerobic cultivation of a natural E. gracilis isolate with the addition of an elongase inhibitor (Tucci et al., 2010).

Furthermore, substantial research has been performed to improve the WE yields specifically. For example, a multi-step cultivation process has been developed on a laboratory scale (in flasks) aiming to maximise WE synthesis. In the first step of this process, E. gracilis is cultivated under inexpensive PT conditions (Arashida and Mitra, 2015). Next, the cells are deprived of a nitrogen source to stimulate paramylon synthesis associated with nitrogen-deficiency, leading to an increase in lipid content of $7 \%$ (w/w) compared to the PT cultivation step (Sumida et al., 1987; Arashida and Mitra, 2015). In the third step, WE synthesis from paramylon is induced by changing to anaerobic cultivation. This is followed by the extraction of the WEs with an organic solvent and column purification, resulting in the production of a source of biofuel (Arashida and Mitra, 2015; Matos, 2017).

In recent years, a growing number of cytometry approaches have been developed for the screening of E. gracilis mutant strains with an increased lipid content. For example, intracellular lipids of a mutant strain generated by Fe-ion irradiation of the WT parental strain were stained with a boron-dipyrromethene dye (BODIPY ${ }^{505 / 515}$ ) to isolate high-producers using fluorescenceactivated cell sorting. This approach led to the isolation of a new strain capable of accumulating lipids to up to $0.2 \mathrm{~g} / \mathrm{g}$ DW under hypoxic cultivation conditions, which represents a $40 \%(\mathrm{w} / \mathrm{w})$ increase in lipid content compared to the original strain (Yamada et al., 2016). Other current cytometry-based techniques are capable of identifying phenotypes of single cells associated with a high lipid content directly. Two examples are high-throughput optofluidic image cytometry, where lipid-overproducing mutants can be identified without the need for staining of the cells with potentially phenotype-altering dyes, and fluorescence imaging flow cytometry, which allows the normalisation of fluorescence values against the cell size to avoid false-negative results (i.e., mislabelling of small cells with relatively high fluorescence values) (Lei et al., 2016; Muñoz et al., 2018).

Besides random mutagenesis, targeted silencing of single genes has shown potential for improving WE yields. For example, knock-down of the starch degradation kinases 1 and 2 using RNAi was shown to lead to a 1.2 and 1.4 -fold increase in WE accumulation, respectively, under anaerobic growth conditions (Kimura and Ishikawa, 2018). As another target for a metabolic engineering approach, trans-2-enoyl-CoA reductase has been identified as a potentially rate-limiting enzyme in the FA synthesis pathway of E. gracilis (Inui et al., 2017).

\section{Paramylon}

\section{Biosynthesis of Paramylon}

Paramylon is the water-insoluble storage polysaccharide of $E$. gracilis, which consists of $\beta$-1,3-linked glucose subunits, and has an estimated molecular weight between 100 and $500 \mathrm{kDa}$ (Figure 3A) (Miyatake and Kitaoka, 1983; Koizumi et al., 1993; Barsanti et al., 2011). Paramylon molecules are arranged as an intermolecular triple helix forming microfibrils, which in turn make up fibres. Rectangular and wedge-shaped segments consisting of these fibres are arranged to form granules, which can be synthesised by $E$. gracilis in different shapes like ellipses or rods (Figure 3B). The granules are $\sim 1-6 \mu \mathrm{m}$ long, surrounded by a biomembrane and show an unusual high degree of crystallinity, setting them apart from other carbohydrate storage products found in plants and algae (Miyatake and Kitaoka, 1983; Koizumi et al., 1993; Bäumer et al., 2001; Barsanti et al., 2011; Monfils et al., 2011).

E. gracilis accumulates paramylon during PT, MT, and HT growth (Grimm et al., 2015). Cultivation under strict HT conditions leads to increased paramylon levels during the exponential growth phase, while light has been shown to be detrimental to the accumulation and conservation of paramylon under MT growth, probably because the metabolic switch to paramylon degradation is under the influence of a photoreceptor (Kiss et al., 1986; Barsanti et al., 2001). One of the highest paramylon titres reported ( $16 \mathrm{~g} / \mathrm{L}$ culture) was obtained in a repeated-batch cultivation under HT conditions in the dark (Table 1), using a medium supplemented with potato liquor, vitamins, and a high concentration of glucose (30 g/L) (Šantek et al., 2012; Grimm et al., 2015).

\section{Paramylon as Feedstock for Biomaterials and Biofuels}

Various industrial applications have been proposed for paramylon, including its use as a substrate for thermoplasticisation. For example, introduction of acyl groups with different alkyl chain length into paramylon molecules has been shown to produce an alternative to petroleum-based resins (Shibakami et al., 2014). Another example is the production of self-assembling $\beta$-1,3-glucan nanofibres derived from paramylon (Shibakami et al., 2013a). The nanofibres can be surfacemodified with functional groups (e.g., carboxylic acid) and could serve as stimuli-responsive polymers or drug delivery systems (Shibakami et al., 2013b). Also, it has been suggested to use paramylon myristate as an "all-natural" pressure-sensitive adhesive (Shibakami and Sohma, 2018).

Microalgal biomass is considered a third-generation biofuel feedstock, not only because of its potentially high lipid content, but also because of the high amounts of complex carbohydrates (e.g., cellulose) that can be produced by many algal species (Lee and Lavoie, 2013). These complex carbohydrates can be hydrolysed chemically into their constituent monosaccharide units (e.g., glucose) for subsequent fermentation to bioethanol, or alternatively using enzymes, as harsh chemical conditions can interfere with fermentation (Mussatto et al., 2010; Chen et al., 2013; Al Abdallah et al., 2016). In principle, enzymatic hydrolysis and conversion processes could be applied to paramylon. 
A

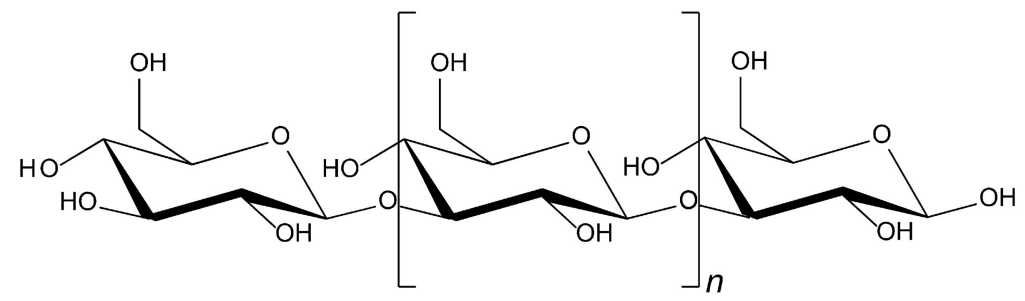

B

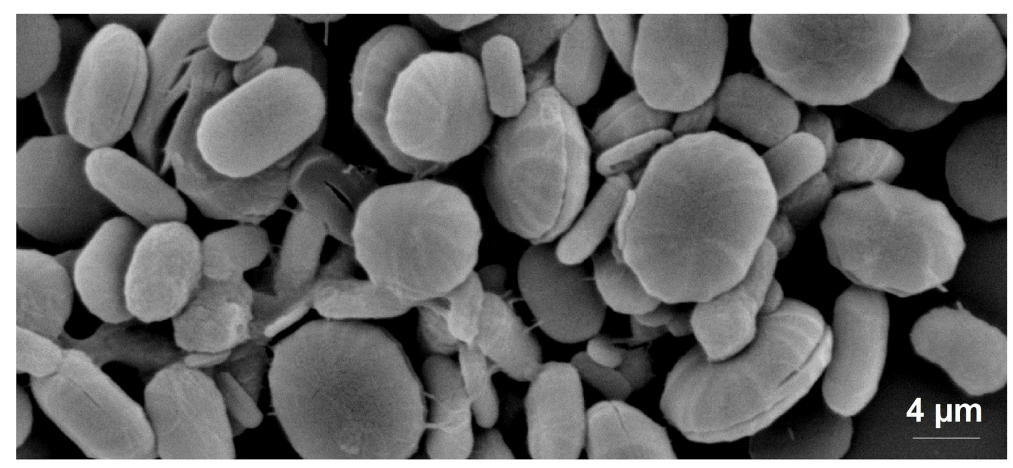

C

$\triangle-(P)$

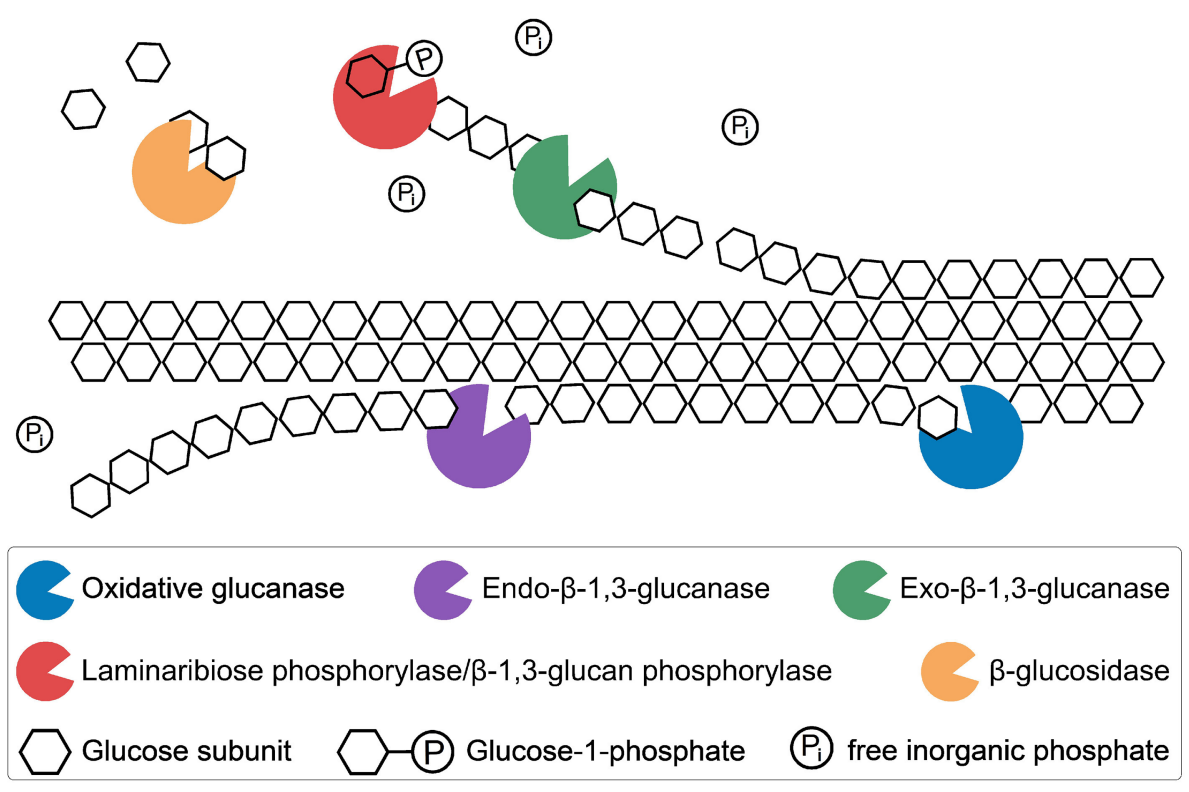

FIGURE 3 | Molecular structure of paramylon (A). $\beta$-1,3-glucan chain ( 700 $\leq n \geq 3,000)$ (Miyatake and Kitaoka, 1983; Koizumi et al., 1993; Barsanti et al., 2011). Microscopic image of paramylon granules (B). Shown are ellipses and rods without biomembrane (Bäumer et al., 2001; Monfils et al., 2011). Putative enzymatic mechanism for synergistic paramylon degradation in Euglena gracilis (C). Enzymes, substrates and products are shown. Oxidative glucanases: cleavage of crystalline paramylon to make it accessible for other enzymes, possibly similar to oxidative cleavage of cellulose (Johansen, 2016). Hydrolytic endo- $\beta$-1,3-glucanases: random cleavage of the polysaccharide chain (Takeda et al., 2015). Hydrolytic exo- $\beta-1,3-$ glucanases and $\beta$-glucosidases: oligoglucans and single glucose units are cleaved off, respectively, at the ends of accessible and freed polysaccharide chains, comparable to the cellulolytic enzymes from Trichoderma reesei (Barras and Stone, 1969; Jeng et al., 2011; Keshavarz and Khalesi, 2016). Laminaribiose phosphorylase/ $\beta-1,3-$ glucan phosphorylase: cleaving of laminaribiose/laminarioligosaccharides into glucose/laminarioliosaccharides and glucose-1-phosphate, which requires free inorganic phosphate (Marechal, 1967; Kuhaudomlarp et al., 2018).

However, paramylon granules have been shown to be recalcitrant to enzymatic degradation and it is very likely that a consortium of different enzymes is required for the efficient degradation of this polysaccharide (Sutivisedsak et al., 2013). So far, only two E. gracilis enzymes involved in paramylon degradation have been characterised, an endo- $\beta$-1,3-glucanase and a laminaribiose phosphorylase (LBP)/ $\beta$-1,3-glucan phosphorylase $(\beta-1,3-\mathrm{GP})$ involved in paramylon degradation have been characterised 
(Vogel and Barber, 1968; Takeda et al., 2015; Kuhaudomlarp et al., 2018). A putative enzymatic mechanism for complete synergistic hydrolysis of the polysaccharide paramylon to glucose is shown in Figure 3C.

Other organisms, mostly belonging to the fungal genera Trichoderma and Aspergillus, have been explored as alternative sources for paramylon-degrading enzymes. For example, a fractionation of enzymes secreted by T. harzianum Rifai PAMB86 led to the enrichment of $\beta$-1,3-glucanases able to degrade paramylon to some degree, yielding mostly glucose (Giese et al., 2011; Sutivisedsak et al., 2013).

Biogas and bio-oil can also be produced from microalgal carbohydrates via thermochemical conversion processes like gasification at high temperatures or pyrolysis in the absence of oxygen, respectively (Behera et al., 2014). Another way to produce biogas consisting mostly of methane from microalgal biomass is through anaerobic digestion by a consortium of microorganisms. Euglena gracilis cell mass has been shown to be a suitable source for the production of biogas by anaerobic digestion, producing around 650 or $800 \mathrm{~mL}$ biogas/g DW under PT or HT cultivation conditions, respectively (Grimm et al., 2015). These yields were up to 10-fold higher than those obtained from microalgae such as Chaetomorpha litorea, Chlamydomonas reinhardtii, Durvillaea antarctica, Macrocystis pyrifera, and Scenedesmus obliquus (Table 1) (Behera et al., 2014).

At this time, microalgae-derived biofuels are not economically feasible because they are not competitive with fossil fuels due to their higher production costs. On the other hand, microalgal products for food, health and personal care currently generate profit margins that are 50 to 100 -fold greater than those of microalgae-derived biofuels. Consequently, it may be a viable commercial strategy to use E. gracilis to produce these high-value products with biofuel commodities as a co-product (Barsanti and Gualtieri, 2018).

\section{Application of Paramylon in Nutrition and Biomedicine}

There are several health benefits associated with $\beta$-glucans, including immunostimulatory and antioxidant effects (Barsanti et al., 2011). They also act as a dietary fibre and have been shown to lower blood cholesterol levels (Nakashima et al., 2018b). Mouse and rat studies, as well as experiments with different mammalian cell lines have been performed to determine the potential impact of the $\beta$-1,3-glucan paramylon on human health. For example, mice fed with $2 \%(\mathrm{w} / \mathrm{w})$ paramylon in their diet and challenged with the (human) influenza virus $A / P R / 8 / 34$ (H1N1) showed higher survival rates and cytokine levels (IFN$\gamma$ IL-1 $\beta$, IL-6, IL-10, and IL-12) compared to the control group in concurrence with lower virus titres, suggesting that paramylon served as an effective regulator of the immune response providing protection against the virus (Nakashima et al., 2017). In a similar study, mice were provided with a diet containing lower than $1 \%(\mathrm{w} / \mathrm{w})$ paramylon and challenged with a potentially lethal dose of E. coli. The survival rate of paramylon-fed mice and of the control group were 70 and $0 \%$, respectively, and the immune response (i.e., antibody titres, IL-2 production, natural killer cell cytotoxicity, and phagocytosis activity) was significantly increased in the group fed with paramylon. The performance of paramylon in this study was as effective as or more effective than two commercially available $\beta$-glucan products for animal feed that were derived from yeast (Levine et al., 2013).

Furthermore, there are effects attributed to paramylon beyond the immune response to pathogens. For example, mice treated with 2,4,6-trinitrochlorobenzene, which would usually induce atopic dermatitis $(\mathrm{AD})$-like skin lesions, were fed with paramylon at $1 \%(\mathrm{w} / \mathrm{w})$ of their diet. Paramylon inhibited the development of AD-like skin lesions, reduced cytokine (IFN- $\gamma$, IL-4, IL-12, and IL-18) levels and dermatitis scores. Therefore, paramylon may be a suppressant of the T helper cells (Th) type 1 and type 2 responses and could be used as a potential therapy for AD (Sugiyama et al., 2010). Another indicator that paramylon has regulatory effects on the cells was a study on a collageninduced arthritis mouse model (for rheumatoid arthritis), where $2 \%(\mathrm{w} / \mathrm{w})$ paramylon in the diet relieved arthritis symptoms and decreased cytokine (IFN- $\gamma$, IL-6, and IL-17) levels, so the authors concluded a possible involvement of Th type 17 cells (Suzuki et al., 2018). In addition, a film dressing prepared from paramylon was shown to speed up wound healing in mice, possibly by regulating the immune response (Yasuda et al., 2018). Paramylon also can act as a potent antioxidant protecting mice from acute hepatic injury induced by $\mathrm{CCl}_{4}$ treatment and was shown to alleviate non-alcoholic steatohepatitis in mice caused by a combination of streptozocin injection and high fat diet when orally administered at a dosage of 1 or $3 \mathrm{~g} / \mathrm{kg}$ bodyweight (BW) per day, respectively (Sugiyama et al., 2009; Nakashima et al., 2018a). Moreover, feeding male rats with $20 \mathrm{mg}$ paramylon/kg BW daily was shown to improve the quality of their sperm (e.g., motility, vitality, and acrosome integrity) (Ak Sonat et al., 2018).

Remarkably, paramylon has been shown to reduce the risk of cancer. For example, when preneoplastic aberrant crypt foci (marker for colon cancer risk) were induced in the colon of mice by 1,2-dimethylhydrazine treatment, the subsequent inclusion of $2 \%(\mathrm{w} / \mathrm{w})$ paramylon into their diet reduced the development of colon cancer by 50\% (Bird, 1995; Watanabe et al., 2013). The mechanisms responsible for this observed reduction are still unclear, but may be related to an effect of paramylon on the gut microbiome (Watanabe et al., 2013).

Until now, the research on the health benefits of paramylon has focussed mainly on applications to treat human conditions, but it has been suggested that it also could be beneficial to livestock and fish health. Studies undertaken with porcine leucocytes, chickens (broilers) and fishes (e.g., rainbow trout, Nile tilapia, and red drum) have shown that supplementation of the medium with paramylon or inclusion of paramylon in a diet resulted in immunostimulatory and/or -regulatory activity on the cells or animals, with positive effects such as host protection against parasites (Sonck et al., 2010; Skov et al., 2012; Levine et al., 2018; Yamamoto et al., 2018a,b). However, more studies would be needed to elucidate the nature of the observed effects and to confirm quantifiable benefits for the animals.

Chemical derivatives of paramylon (activated paramylon) have been shown to exhibit augmented or novel bioactivities. For example, the antimicrobial activity of paramylon was enhanced chemically by introducing positively charged groups (e.g., 
2-hydroxy-3-trimethylammoniopropyl, N,N-diethylaminoethyl, and $\mathrm{N}, \mathrm{N}$-dimethylaminoethyl groups) and sulphated paramylon was shown to exhibit anti-HIV activity (Sakagami et al., 1989; Koizumi et al., 1993). It was also shown that topical treatment of paramylon conjugated with hyaluronic acid at a concentration of $200 \mathrm{mg} / \mathrm{mL}$ can promote wound healing in rats to a higher degree than native paramylon. As a result, corneal epithelial cell migration was increased and the acute inflammatory reaction caused by corneal alkali burns in vivo was supressed (Choi et al., 2013). Furthermore, it was shown in vitro and in a mouse model that straight-chain cationic 2-hydroxy-3-(trimethylammonio)propyl paramylon (HTAP) is capable of effectively sequestering bile salts, indicating an anti-diabetic effect, and the bodyweight of obese mice was reduced when the feed was supplemented with $2 \%(\mathrm{w} / \mathrm{w})$ HTAP (Shibakami et al., 2018).

Incubation of originally granular paramylon with bases like sodium hydroxide has been shown to yield soluble nanofibers. There are strong indications that this pretreatment of paramylon has the effect of an increase in stimulation of leucocytes and hepatoprotection, probably because the $\beta$-1,3-glucan triplehelices of paramylon are disrupted in the process and the apparently more bioactive single helices are thereby exposed (Kataoka et al., 2002; Kusmic et al., 2018). Accordingly, alkalised paramylon was shown to upregulate proinflammatory factors (COX-2, IL-6, NO, TNF- $\alpha$ and translocation of NF- $\kappa$ B) in human lymphomonocytes at a higher rate than the similarly treated commercial $\beta$-glucan product MacroGuard, which is derived from S. cerevisiae (Russo et al., 2017).

To maximise the bioactive potential of paramylon, the granules could be hydrolysed to soluble shorter-chain $\beta-1,3$ glucans, which may lead to an increased blood plasma availability and a stronger or different immune response compared to an insoluble preparation (Rice et al., 2005). Only recently, it has been shown that microwave pretreatment of the granules can be used to enhance the activity of paramylon-degrading enzymes, yielding soluble immunostimulating hydrolysis products (Gissibl et al., 2018).

The in vitro synthesis of soluble $\beta$-1,3-glucans could be an alternative to the hydrolysis approach. However, the current chemical synthesis of oligosaccharides is still laborious and product yields are very low despite some advances in the field, whereas enzymatic synthesis has been considered as a technically feasible option (Plante et al., 2001; Ogawa et al., 2014). Towards this end, an E. gracilis $\beta$-1,3-glycosyl transferase (paramylon synthase) complex has been purified, characterised, and shown to convert uridine diphosphate $\mathrm{D}$-glucose into $\beta$-1,3-glucan. Unfortunately, the product yield of this reaction has not been reported (Bäumer et al., 2001). Alternatively, the reversal of the equilibrium reaction of the LBP/ $\beta-1,3-\mathrm{GP}$ (see Figure 3 ) has been proposed as a way of synthesising short-chain $\beta$-1,3-glucans, using initially glucose and subsequently glucose-1-phosphate as substrates (Kitaoka et al., 1993; Kuhaudomlarp et al., 2018). Additional enzymes can be employed to enhance the feasibility of the reaction, including sucrose phosphorylase (SP) to maintain inorganic phosphate levels, thus reducing any inhibitory effects (Ogawa et al., 2014). In a further development of this system, the reusability of $\mathrm{LBP} / \beta-1,3-\mathrm{GP}$ was demonstrated following covalent immobilisation onto solid support enzyme carriers or formation of cross-linking of enzyme aggregates. However, the product (laminaribiose) yield of the immobilisation approach in combination with the SP enzyme was just 20\% (w/w) (Müller et al., 2016).

Despite substantial evidence for the health-enhancing bioactivities of paramylon and paramylon-derived compounds as outlined above, we are not aware of any clinical studies confirming these claims. By definition, paramylon and its related compounds can only be considered 'nutraceuticals' and not 'pharmaceuticals', which has restricted them to be used only as food supplements (Santini et al., 2018). Currently, the healthenhancing properties of paramylon are exploited in this way by several new or already established companies in Japan and the United States, which are selling paramylon-rich E. gracilis whole cell meal or extracted paramylon (Barsanti and Gualtieri, 2018).

\section{LARGE-SCALE CULTIVATION OF E. GRACILIS}

\section{Towards Industrial-Scale Cultivation}

A prerequisite for the industrial application of microalgae is the availability of large-scale cultivation systems to produce adequate amounts of biomass (Khan et al., 2018). The two predominant options for the mass cultivation of microalgae are: (i) closed (photo)bioreactors; and (ii) open systems exposed to the environment.

Preliminary laboratory-scale experiments to determine $E$. gracilis biomass yields from $\mathrm{PT}, \mathrm{MT}$ and $\mathrm{HT}$ cultivations in shake flasks or bench-scale bioreactors can be used to assess the potential scale-up of production processes. HT cultivation with glucose as a carbon source in shake flasks usually reaches DW titres of $\sim 12$ g/L culture, whereas repeatedbatch cultivation supplemented with potato liquor and glucose in a bioreactor ( $5 \mathrm{~L}$ working volume) was shown to reach $\sim 23$ g/L culture (Šantek et al., 2012; Grimm et al., 2015; Hasan et al., 2017). A maximum E. gracilis biomass titre of $\sim 48 \mathrm{~g} \mathrm{DW} / \mathrm{L}$ culture was achieved in a fed-batch HT cultivation strictly in the dark, using a jar fermenter $(2 \mathrm{~L}$ working volume) with glucose concentrations kept constantly above $1 \mathrm{~g} / \mathrm{L}$ (Ogbonna et al., 1998). As some microalgal species, including Chlorella sp. and Crypthecodinium cohnii, have been shown to reach more than twice the DW of $E$. gracilis under HT cultivation (Table 1), the current E. gracilis HT cultivation process should be revised to improve its efficiency (Bumbak et al., 2011).

DW titres per L of MT cultures have been shown to fall short of HT cultures in comparative experiments by around $30 \%(w / w)$, although it has been suggested that the PT and HT metabolisms could complement each other under MT conditions (Ogbonna et al., 2002; Hasan et al., 2017). PT cultivation produces $\sim 20$-fold less biomass (between 2 and $3 \mathrm{~g}$ DW/L culture) compared to HT and MT cultivation (Table 1) (Grimm et al., 2015; Hasan et al., 2017). Attempts to enhance E. gracilis biomass production under PT conditions, for example with the use of a photobioreactor, resulted in maximum titres similar to those of shake flask 
cultures, which are several times lower than those of some microalgal species grown under closed PT conditions (Table 1) (Richmond et al., 2003; Chae et al., 2006; Hasan et al., 2017).

Outdoor PT cultivation is considered the most economical option for the bulk production of microalgal biomass (Apel and Weuster-Botz, 2015). However, there are a number of prerequisites for open PT cultivation, including the availability of at least 3,000 ha of usable land area, $3 \mathrm{~h}$ of average sunlight per day, $500 \mathrm{~mm}$ annual rainfall and a tropical/dry/temperate climate. In Japan, an open pond system $(30 \mathrm{~m}$ in diameter, $20 \mathrm{~cm}$ deep and stirred for aeration) for commercial PT cultivation of $E$. gracilis has been shown to be economically feasible and it can be expected that outdoor systems would be easily implemented in other countries such as Australia, Brazil, Malaysia, Thailand, the USA and Vietnam (Suzuki, 2017). Open ponds are low-tech solutions and potentially cheaper when compared to technically more demanding open systems like raceway tanks, which in turn promise higher yields (Apel and Weuster-Botz, 2015). In a laboratory set-up mimicking local environmental conditions, experiments with a raceway for the $\mathrm{PT}$ cultivation of E. gracilis resulted in biomass yields close to calculated theoretical values. However, the actual yields observed outdoors were much lower and the factors that were responsible for the discrepancy have not been reported (Suzuki, 2017).

\section{Challenges and Possible Solutions}

Reports on industrial-scale HT cultivation of E. gracilis in controlled bioreactors have been only conceptual so far. For example, Levine et al. have proposed a multi-stage process where smaller bioreactors generate the inocula for the bigger stages (up to $1,000,000 \mathrm{~L}$ ) with the aim to increase biomass titres to 120 g/L culture or higher (Levine et al., 2013). This biomass yield would be comparable to or higher than those obtained with some microalgae grown under HT conditions (Table 1) (Bumbak et al., 2011). However, there is no further information on whether this proposed system was ever built and tested. It is likely that certain disadvantages of HT cultivation prevented its realisation such as the cost of the medium containing an organic carbon source like glucose (Šantek et al., 2010). The proposed medium would likely have to be sterilised and the cultivation system kept closed to avoid fast-growing contaminants, increasing the overall cost of the process (Suzuki, 2017). The use of wastewater, municipal organic waste, compost or nutrition-rich waste products from the food industry such as potato liquor or dairy effluent could lower the costs by replacing or supplementing the HT growth medium with the additional benefit of potentially bioremediating these effluents (Šantek et al., 2012; Mahapatra et al., 2013; Yadavalli et al., 2014; Torihara and Kishimoto, 2015; Tossavainen et al., 2018).

PT cultivation on the other hand, although being a feasible alternative to HT cultivation, is restricted by low yields even after the technical optimisation of the cultivation process (Chae et al., 2006; Grimm et al., 2015; Hasan et al., 2017; Suzuki, 2017). A solution to this problem could be the genetic modification (GM) of E. gracilis to improve biomass and/or bioproduct yields. For example, expression of the Synechococcus elongatus
PCC 7942 fructose-1,6-/sedoheptulose-1,7-bisphosphatase gene in E. gracilis chloroplasts was shown to significantly enhance its photosynthetic activity, as well as the paramylon yield (by almost 2-fold), the WE yield under anaerobic conditions ( $\sim 100$-fold) and the biomass yield ( $\sim 2$-fold) (Ogawa et al., 2015). However, local legal regulations could prevent (outdoor) cultivation of genetically modified E. gracilis strains (Beacham et al., 2017). Alternatively, conventional mutagenesis could be used to generate 'natural' mutant strains with desired traits, a process which is generally not considered GM. Several reports have described the successful mutagenesis (e.g., by irradiation) of E. gracilis (Schiff et al., 1980; Yamada et al., 2016; Suzuki, 2017).

A major limitation facing the industrial-scale production of $E$. gracilis biomass is vitamin auxotrophy. Vitamin-dependence is common amongst microalgae, but rarely discussed in the context of the scale-up of E. gracilis cultivation (Croft et al., 2006). Euglena gracilis shows an absolute requirement for vitamins $\mathrm{B}_{1}$ (thiamine) and $\mathrm{B}_{12}$ (cobalamin), so complex E. gracilis media usually contain at least $50 \mathrm{ng} / \mathrm{L}$ and $10 \mathrm{ng} / \mathrm{L}$, respectively, of these compounds (Isegawa et al., 1987; Shigeoka et al., 1987; Croft et al., 2005; Hasan et al., 2017). Accordingly, the supplementation of both vitamins, produced either by chemical synthesis (thiamine) or extracted from bacterial sources (cobalamin), would be a factor in a scaled-up E. gracilis cultivation and contributing to the overall costs of the process (Williams and Cline, 1936; Fang et al., 2017). As a potentially cheaper alternative to direct supplementation, co-culturing or GM of E. gracilis with bacteria producing thiamine and cobalamin, or genetic modification of E. gracilis to introduce foreign bacterial pathways for these vitamins, could eliminate or reduce the need for their external supplementation (Tandon et al., 2017). Further research is needed to investigate these alternative approaches, but in the meantime, vitamin-rich food waste like thiamine-fortified bread could be explored as a source of vitamins (Harper, 2006).

\section{CONCLUSIONS}

There is an emerging market for E. gracilis-derived products, which is reflected in the recent founding of new companies specialised in the cultivation and commercialisation of E. gracilis. PT cultivation of E. gracilis is currently favoured, probably due to lower cost and relative ease of set-up, but HT cultivation for higher yields of cell mass and paramylon could soon become reality. Presently, only nutritious whole cell meal, the nutraceutical paramylon and cosmetics are commercially viable, while biofuel production from $E$. gracilis cell mass is in contrast not yet feasible. However, carbohydrate and lipid yields in E. gracilis can be improved by new cultivation technologies and metabolic engineering approaches, possibly providing an affordable alternative to fossil fuels in the near future.

\section{AUTHOR CONTRIBUTIONS}

Original data collection and draft preparation by AG. All authors listed have made a direct and intellectual contribution to the work and approved it for publication. 


\section{FUNDING}

This work was supported by the Australian Research Council Industrial Transformation Training Centre funding scheme (Project Number: IC130100009). AG was supported by an international Macquarie University Research Excellence Scholarship. AC is supported by a

\section{REFERENCES}

Aghajanian, P., Hall, S., Wongworawat, M.D., and Mohan, S. (2015). The roles and mechanisms of actions of vitamin $\mathrm{C}$ in bone: new developments. J. Bone Mineral Res. 30, 1945-1955. doi: 10.1002/jbmr.2709

Ak Sonat, F., Alcay, S., Toker, M.B., Peker, S., and Ustuner, B. (2018). The effects of dietary restriction and administration of $\beta$-glucan from Euglena gracilis on the sperm characteristics and reproductive organs of rats. Andrologia 50:e13088. doi: 10.1111 /and.13088

Al Abdallah, Q., Nixon, B.T., and Fortwendel, J.R. (2016). The enzymatic conversion of major algal and cyanobacterial carbohydrates to bioethanol. Front. Energy Res. 4, 1-15. doi: 10.3389/fenrg.2016.00036

Andreani, L., and Rocha, J.D. (2012). Use of ionic liquids in biodiesel production: a review. Braz. J. Chem. Eng. 29, 1-13. doi: 10.1590/S0104-66322012000100001

Apel, A.C., and Weuster-Botz, D. (2015). Engineering solutions for open microalgae mass cultivation and realistic indoor simulation of outdoor environments. Bioprocess Biosyst. Eng. 38, 995-1008. doi: 10.1007/s00449-015-1363-1

Arashida, R., and Mitra, S. (2015). Method for Production of Euglena Containing Wax Ester at High Content, and Method for Production of Wax Ester. U.S. Patent No 9,045,784. Washington, DC: United States Patent and Trademark Office.

Barras, D.R., and Stone, B.A. (1969). $\beta$-1,3-glucan hydrolases from Euglena gracilis: II. Purification and properties of the $\beta$-1,3-glucan exo-hydrolase. Biochim. Biophys. Acta (BBA) Enzymol. 191, 342-353. doi: 10.1016/0005-2744(69)90253-8

Barsanti, L., Bastianini, A., Passarelli, V., Tredici, M.R., and Gualtieri, P. (2000). Fatty acid content in wild type and WZSL mutant of Euglena gracilis. J. Appl. Phycol. 12, 515-520. doi: 10.1023/a:1008187514624

Barsanti, L., and Gualtieri, P. (2018). Is exploitation of microalgae economically and energetically sustainable? Algal Res. 31, 107-115. doi: 10.1016/j.algal.2018.02.001

Barsanti, L., Passarelli, V., Evangelista, V., Frassanito, A.M., and Gualtieri, P. (2011). Chemistry, physico-chemistry and applications linked to biological activities of $\beta$-glucans. Nat. Prod. Rep. 28, 457-466. doi: 10.1039/C0NP00018C

Barsanti, L., Vismara, R., Passarelli, V., and Gualtieri, P. (2001). Paramylon ( $\beta$-1,3glucan) content in wild type and WZSL mutant of Euglena gracilis. Effects of growth conditions. J. Appl. Phycol. 13, 59-65. doi: 10.1023/a:1008105416065

Bäumer, D., Preisfeld, A., and Ruppel, H.G. (2001). Isolation and characterization of paramylon synthase from Euglena gracilis (Euglenophyceae). J. Phycol. 37, 38-46. doi: 10.1046/j.1529-8817.2001.037001038.x

Beacham, T.A., Sweet, J.B., and Allen, M.J. (2017). Large scale cultivation of genetically modified microalgae: a new era for environmental risk assessment. Algal Res. 25, 90-100. doi: 10.1016/j.algal.2017.04.028

Behera, S., Singh, R., Arora, R., Sharma, N.K., Shukla, M., and Kumar, S. (2014). Scope of algae as third generation biofuels. Front. Bioeng. Biotechnol. 2, 1-13. doi: 10.3389 /fbioe. 2014.00090

Bird, R.P. (1995). Role of aberrant crypt foci in understanding the pathogenesis of colon cancer. Cancer Lett. 93, 55-71. doi: 10.1016/0304-3835(95)0 3788-X

Buetow, D.E. (2011). Euglena. Hoboken: John Wiley \& Sons, Ltd.

Bumbak, F., Cook, S., Zachleder, V., Hauser, S., and Kovar, K. (2011). Best practices in heterotrophic high-cell-density microalgal processes: achievements, potential and possible limitations. Appl. Microbiol. Biotechnol. 91, 31-46. doi: 10.1007/s00253-011-3311-6

Chae, S.R., Hwang, E.J., and Shin, H.S. (2006). Single cell protein production of Euglena gracilis and carbon dioxide fixation in an innovative photo-bioreactor. Bioresource Technol. 97, 322-329. doi: 10.1016/j.biortech.2005.02.037
Cancer Institute New South Wales Early Career Fellowship (Project Number: ECF171114).

\section{ACKNOWLEDGMENTS}

We would like to thank the Macquarie University Microscopy Unit for its contribution to Figure 3.

Chen, C.-Y., Zhao, X.-Q., Yen, H.-W., Ho, S.-H., Cheng, C.-L., Lee, D.-J., et al (2013). Microalgae-based carbohydrates for biofuel production. Biochem. Eng. J. 78, 1-10. doi: 10.1016/j.bej.2013.03.006

Choi, J.A., Oh, T.-H., Choi, J.-S., Chang, D.-J., and Joo, C.-K. (2013). Impact of $\beta$-1,3-glucan isolated from Euglena gracilis on corneal epithelial cell migration and on wound healing in a rat alkali burn model. Curr. Eye Res. 38, 1207-1213. doi: 10.3109/02713683.2013.811262

Croft, M.T., Lawrence, A.D., Raux-Deery, E., Warren, M.J., and Smith, A.G. (2005). Algae acquire vitamin $B_{12}$ through a symbiotic relationship with bacteria. Nature 438, 90. doi: 10.1038/nature04056

Croft, M.T., Warren, M.J., and Smith, A.G. (2006). Algae need their vitamins. Eukaryot. Cell 5, 1175-1183. doi: 10.1128/ec.00097-06

Damude, H.G., McGonigle, B., Qun Zhu, Q., and Xue, , Z. (2010). Delta-9 Elongases and Their Use in Making Polyunsaturated Fatty Acids. U.S. Patent No 7.645,604. Washington, DC: United States Patent and Trademark Office.

de Oliveira, M.A.C.L., Monteiro, M.P.C., Robbs, P.G., and Leite, S. (1999). Growth and chemical composition of Spirulina maxima and Spirulina platensis biomass at different temperatures. Aquacult. Int. 7, 261-275. doi: 10.1023/A:1009233230706

Deckelbaum, R.J., and Torrejon, C. (2012). The omega-3 Fatty acid nutritional landscape: health benefits and sources. J. Nutr. 142, 587S-591S. doi: $10.3945 /$ jn. 111.148080

Disch, A., Schwender, J., Müller, C., Lichtenthaler, H.K., and Rohmer, M. (1998) Distribution of the mevalonate and glyceraldehyde phosphate/pyruvate pathways for isoprenoid biosynthesis in unicellular algae and the cyanobacterium Synechocystis PCC 6714. Biochem. J. 333, 381-388. doi: 10.1042/bj3330381

Doetsch, N.A., Favreau, M.R., Kuscuoglu, N., Thompson, M.D., and Hallick, R.B. (2001). Chloroplast transformation in Euglena gracilis: splicing of a group III twintron transcribed from a transgenic psbK operon. Curr. Genet. 39, 49-60. doi: $10.1007 / \mathrm{s} 002940000174$

Dragosits, M., and Mattanovich, D. (2013). Adaptive laboratory evolution principles and applications for biotechnology. Microb. Cell Factories 12, 1-17. doi: 10.1186/1475-2859-12-64

Ebenezer, T.E., Zoltner, M., Burrel, A., Nenarokova, A., Anna, Vanclová, M.G.N., et al. (2017). Unlocking the biological potential of Euglena gracilis: evolution, cell biology and significance to parasitism. bioRxiv 2017, 1-59. doi: $10.1101 / 228015$

Fang, H., Kang, J., and Zhang, D. (2017). Microbial production of vitamin $\mathrm{B}_{12}$ : a review and future perspectives. Microb. Cell Factories 16, 1-14. doi: 10.1186/s12934-017-0631-y

Fritsche, S., Wang, X., and Jung, C. (2017). Recent advances in our understanding of tocopherol biosynthesis in plants: an overview of key genes, functions, and breeding of vitamin E improved crops. Antioxidants 6, 1-18. doi: 10.3390/antiox6040099

Fujita, T., Aoyagi, H., Ogbonna, J.C., and Tanaka, H. (2008). Effect of mixed organic substrate on $\alpha$-tocopherol production by Euglena gracilis in photoheterotrophic culture. Appl. Microbiol. Biotechnol. 79, 371-378. doi: 10.1007/s00253-008-1443-0

Furuhashi, T., Ogawa, T., Nakai, R., Nakazawa, M., Okazawa, A., Padermschoke, A., et al. (2015). Wax ester and lipophilic compound profiling of Euglena gracilis by gas chromatography-mass spectrometry: toward understanding of wax ester fermentation under hypoxia. Metabolomics 11, 175-183. doi: $10.1007 /$ s11306-014-0687-1

García-García, J.D., Girard, L., Hernández, G., Saavedra, E., Pardo, J.P., Rodríguez-Zavala, J.S., et al. (2014). Zn-bis-glutathionate is the best cosubstrate of the monomeric phytochelatin synthase from the photosynthetic 
heavy metal-hyperaccumulator Euglena gracilis. Metallomics 6, 604-616. doi: 10.1039/C3MT00313B

García-García, J.D., Peña-Sanabria, K.A., Sánchez-Thomas, R., and MorenoSánchez, R. (2018). Nickel accumulation by the green algae-like Euglena gracilis. J. Hazard. Mater. 343, 10-18. doi: 10.1016/j.jhazmat.2017.09.008

Giese, E., Dekker, R., Barbosa, A., da Silva, M., and da Silva, R. (2011). Production of $\beta$ - $(1,3)$-glucanases by Trichoderma harzianum Rifai: optimization and application to produce gluco-oligosaccharides from paramylon and pustulan. Ferment. Technol. 1, 1-5. doi: 10.4172/2167-7972.1000102

Gissibl, A., Care, A., Parker, L.M., Iqbal, S., Hobba, G., Nevalainen, H., et al. (2018). Microwave pretreatment of paramylon enhances the enzymatic production of soluble $\beta$-1,3-glucans with immunostimulatory activity. Carbohydrate Polymers 196, 339-347. doi: 10.1016/j.carbpol.2018.05.038

Grimm, P., Risse, J.M., Cholewa, D., Müller, J.M., Beshay, U., Friehs, K., et al. (2015). Applicability of Euglena gracilis for biorefineries demonstrated by the production of $\alpha$-tocopherol and paramylon followed by anaerobic digestion. J. Biotechnol. 215, 72-79. doi: 10.1016/j.jbiotec.2015.04.004

Grosso, G., Bei, R., Mistretta, A., Marventano, S., Calabrese, G., Masuelli, L., et al. (2013). Effects of vitamin C on health: a review of evidence. Front. Biosci. 18, 1017-1029. doi: $10.2741 / 4160$

Harper, C. (2006). Thiamine (vitamin $B_{1}$ ) deficiency and associated brain damage is still common throughout the world and prevention is simple and safe! Eur. J. Neurol. 13, 1078-1082. doi: 10.1111/j.1468-1331.2006.01530.x

Hasan, M.T., Sun, A., Mirzaei, M., Te’o, J., Hobba, G., Sunna, A., et al. (2017). A comprehensive assessment of the biosynthetic pathways of ascorbate, $\alpha$ tocopherol and free amino acids in Euglena gracilis var. saccharophila. Algal Res. 27, 140-151. doi: 10.1016/j.algal.2017.08.029

Hayashi, H., Narumi, I., Wada, S., Kikuchi, M., Furuta, M., Uehara, K., et al. (2004). Light dependency of resistance to ionizing radiation in Euglena gracilis. J. Plant Physiol. 161, 1101-1106. doi: 10.1016/j.jplph.2004.04.005

Henchion, M., Hayes, M., Mullen, A., Fenelon, M., and Tiwari, B. (2017). Future protein supply and demand: strategies and factors influencing a sustainable equilibrium. Foods 6, 1-21. doi: 10.3390/foods6070053

Hosotani, K., and Kitaoka, S. (1977). Determination of the nutritive value of Euglena gracilis protein by in vitro digestion experiments and rat feeding tests. Nippon Nogeikagaku Kaishi 51, 483-488. doi: 10.1271 /nogeikagaku1924.51.8_483

Innis, S.M. (2014). Omega-3 fatty acid biochemistry: perspectives from human nutrition. Military Med. 179 (Suppl. 11), 82-87. doi: 10.7205/MILMED-D-14-00147

Inui, H., Ishikawa, T., and Tamoi, M. (2017). "Wax ester fermentation and its application for biofuel production," in Euglena: Biochemistry, Cell and Molecular Biology, eds S. D. Schwartzbach and S. Shigeoka (Cham: Springer International Publishing), 269-283.

Inui, H., Miyatake, K., Nakano, Y., and Kitaoka, S. (1984). Fatty acid synthesis in mitochondria of Euglena gracilis. Eur. J. Biochem. 142, 121-126. doi: 10.1111/j.1432-1033.1984.tb08258.x

Isegawa, Y., Nakano, Y., and Kitaoka, S. (1987). Photosynthesis of Euglena gracilis under cobalamin-sufficient and -limited growing conditions. Plant Physiol. 84, 609-612. doi: 10.1104/pp.84.3.609

Isegawa, Y., Watanabe, F., Kitaoka, S., and Nakano, Y. (1993). Subcellular distribution of cobalamin-dependent methionine synthase in Euglena gracilis Z. Phytochemistry 35, 59-61. doi: 10.1016/S0031-9422(00)90509-0

Ishikawa, T., Masumoto, I., Iwasa, N., Nishikawa, H., Sawa, Y., Shibata, H., et al. (2006). Functional characterization of D-galacturonic acid reductase, a key enzyme of the ascorbate biosynthesis pathway, from Euglena gracilis. Biosci. Biotechnol. Biochem. 70, 2720-2726. doi: 10.1271/bbb.60327

Ishikawa, T., and Shigeoka, S. (2008). Recent advances in ascorbate biosynthesis and the physiological significance of ascorbate peroxidase in photosynthesizing organisms. Biosci. Biotechnol. Biochem. 72, 1143-1154. doi: 10.1271/bbb.80062

Ishikawa, T., Tajima, N., Nishikawa, H., Gao, Y., Rapolu, M., Shibata, H., et al. (2010). Euglena gracilis ascorbate peroxidase forms an intramolecular dimeric structure: its unique molecular characterization. Biochem. J. 426, 125-134. doi: 10.1042/bj20091406

Jeng, W.Y., Wang, N.C., Lin, M.H., Lin, C.T., Liaw, Y.C., Chang, W.J., et al. (2011). Structural and functional analysis of three beta-glucosidases from bacterium Clostridium cellulovorans, fungus Trichoderma reesei and termite Neotermes koshunensis. J. Struct. Biol. 173, 46-56. doi: 10.1016/j.jsb.2010.07.008
Jiang, Q., Christen, S., Shigenaga, M.K., and Ames, B.N. (2001). $\gamma$-tocopherol, the major form of vitamin $\mathrm{E}$ in the US diet, deserves more attention. Am. J. Clin. Nutr. 74, 714-722. doi: 10.1093/ajcn/74.6.714

Johansen, K.S. (2016). Lytic polysaccharide monooxygenases: the microbial power tool for lignocellulose degradation. Trends Plant Sci. 21, 926-936. doi: 10.1016/j.tplants.2016.07.012

Kataoka, H., Shimura, T., Mizoshita, T., Kubota, E., Mori, Y., Mizushima, T., et al. (2009). Lentinan with S-1 and paclitaxel for gastric cancer chemotherapy improve patient quality of life. Hepatogastroenterology 56, 547-550.

Kataoka, K., Muta, T., Yamazaki, S., and Takeshige, K. (2002). Activation of macrophages by linear $(1 \rightarrow 3)-\beta$-D-glucans. Implications for the recognition of fungi by innate immunity. J. Biol. Chem. 277, 36825-36831. doi: 10.1074/jbc.M206756200

Kato, S., Soshino, M., Takaichi, S., Ishikawa, T., Nagata, N., Asahina, M., et al. (2017). Suppression of the phytoene synthase gene $(E g c r t B)$ alters carotenoid content and intracellular structure of Euglena gracilis. BMC Plant Biol. 17, 1-10. doi: 10.1186/s12870-017-1066-7

Kato, S., Takaichi, S., Ishikawa, T., Asahina, M., Takahashi, S., and Shinomura, T. (2016). Identification and functional analysis of the geranylgeranyl pyrophosphate synthase gene ( $c r t E)$ and phytoene synthase gene ( $c r t B)$ for carotenoid biosynthesis in Euglena gracilis. BMC Plant Biol. 16, 1-12. doi: 10.1186/s12870-015-0698-8

Keshavarz, B., and Khalesi, M. (2016). Trichoderma reesei, a superior cellulase source for industrial applications. Biofuels 7, 713-721. doi: 10.1080/17597269.2016.1192444

Khan, M.I., Shin, J.H., and Kim, J.D. (2018). The promising future of microalgae: current status, challenges, and optimization of a sustainable and renewable industry for biofuels, feed, and other products. Microb. Cell Factories 17, 1-21. doi: 10.1186/s12934-018-0879-x

Khatiwada, B., Kautto, L., Sunna, A., Sun, A., and Nevalainen, H. (2019). Nuclear transformation of the versatile microalga Euglena gracilis. Algal Res. 37, 178-185. doi: 10.1016/j.algal.2018.11.022

Kim, D., Filtz, M.R., and Proteau, P.J. (2004). The methylerythritol phosphate pathway contributes to carotenoid but not phytol biosynthesis in Euglena gracilis. J. Nat. Prod. 67, 1067-1069. doi: 10.1021/np049892x

Kimura, M., and Ishikawa, T. (2018). Suppression of DYRK ortholog expression affects wax ester fermentation in Euglena gracilis. J. Appl. Phycol. 30, 367-373. doi: 10.1007/s10811-017-1235-y

Kiss, J.Z., Vasoconcelos, A.C., and Triemer, R.E. (1986). Paramylon synthesis and chloroplast structure associated with nutrient levels in Euglena (Euglenophyceae). J. Phycol. 22, 327-333. doi: 10.1111/j.1529-8817.1986.tb00031.x

Kitaoka, M., Sasaki, T., and Taniguchi, H. (1993). Purification and properties of laminaribiose phosphorylase (EC 2.4. 1.31) from Euglena gracilis Z. Arch. Biochem. Biophys. 304, 508-514. doi: 10.1006/abbi.1993.1383

Koch, M., Lemke, R., Heise, K.-P., and Mock, H.-P. (2003). Characterization of $\gamma$-tocopherol methyltransferases from Capsicum annuum L and Arabidopsis thaliana. Eur. J. Biochem. 270, 84-92. doi: 10.1046/j.1432-1033.2003.03364.x

Koizumi, N., Sakagami, H., Utsumi, A., Fujinaga, S., Takeda, M., Asano, K., et al. (1993). Anti-HIV (human immunodeficiency virus) activity of sulfated paramylon. Antiviral Res. 21, 1-14. doi: 10.1016/0166-3542(93)9 0063-O

Korn, E.D. (1964). The fatty acids of Euglena gracilis. J. Lipid Res. 5, 352-362.

Kuhaudomlarp, S., Patron, N.J., Henrissat, B., Rejzek, M., Saalbach, G., and Field, R.A. (2018). Identification of Euglena gracilis $\beta$-1,3-glucan phosphorylase and establishment of a new glycoside hydrolase (GH) family GH149. J. Biol. Chem. 293, 2865-2876. doi: 10.1074/jbc.RA117.000936

Kusmic, C., Barsacchi, R., Barsanti, L., Gualtieri, P., and Passarelli, V. (1998). Euglena gracilis as source of the antioxidant vitamin E. Effects of culture conditions in the wild strain and in the natural mutant WZSL. J. Appl. Phycol. 10, 555-559. doi: 10.1023/a:1008022305865

Kusmic, C., Barsanti, L., Di Lascio, N., Faita, F., Evangelista, V., and Gualtieri, P. (2018). Anti-fibrotic effect of paramylon nanofibers from the WZSL mutant of Euglena gracilis on liver damage induced by $\mathrm{CCl}_{4}$ in mice. J. Funct. Foods 46 , 538-545. doi: 10.1016/j.jff.2018.05.021

Lee, R.A., and Lavoie, J.-M. (2013). From first- to third-generation biofuels: challenges of producing a commodity from a biomass of increasing complexity. Anim. Front. 3, 6-11. doi: 10.2527/af.2013-0010 
Lei, C., Ito, T., Ugawa, M., Nozawa, T., Iwata, O., Maki, M., et al. (2016). Highthroughput label-free image cytometry and image-based classification of live Euglena gracilis. Biomed. Opt. Express 7, 2703-2708. doi: 10.1364/BOE.7.002703

Levine, R., Horst, G., Tonda, R., Lumpkins, B., and Mathis, G. (2018). Evaluation of the effects of feeding dried algae containing beta-1,3-glucan on broilers challenged with Eimeria. Poultry Sci. 97, 3494-3500. doi: 10.3382/ps/pey227

Levine, R.B., LeBrun, J.R., and Horst, G.P. (2013). Multi-stage Process for Production of Immune Modulator. World Intellectual Property Organization.

Lohr, M., Schwender, J., and Polle, J.E.W. (2012). Isoprenoid biosynthesis in eukaryotic phototrophs: a spotlight on algae. Plant Sci. 185-186, 9-22. doi: 10.1016/j.plantsci.2011.07.018

Mahapatra, D.M., Chanakya, H.N., and Ramachandra, T.V. (2013). Euglena sp. as a suitable source of lipids for potential use as biofuel and sustainable wastewater treatment. J. Appl. Phycol. 25, 855-865. doi: 10.1007/s10811-013-9979-5

Malkoff, D.B., and Buetow, D.E. (1964). Ultrastructural changes during carbon starvation in Euglena gracilis. Exp. Cell Res. 35, 58-68. doi: 10.1016/0014-4827(64)90071-0

Marechal, L.R. (1967). $\beta$-1,3-oligoglucan:orthophosphate glucosyltransferases from Euglena gracilis: II. Comparative studies between laminaribiose- and $\beta$ 1,3-oligoglucan phosphorylase. Biochim. Biophys. Acta (BBA) Enzymol. 146, 431-442. doi: 10.1016/0005-2744(67)90227-6

Matos, Â.P. (2017). The impact of microalgae in food science and technology. J. Am. Oil Chem. Soc. 94, 1333-1350. doi: 10.1007/s11746-017-3050-7

Maurice, L.Q., Lander, H., Edwards, T., and Harrison, W.E. (2001). Advanced aviation fuels: a look ahead via a historical perspective. Fuel 80, 747-756. doi: 10.1016/S0016-2361(00)00142-3

Maxwell, J.R., Douglas, A.G., Eglinton, G., and McCormick, A. (1968). The Botryococcenes - hydrocarbons of novel structure from the alga Botryococcus braunii, Kützing. Phytochemistry 7, 2157-2171. doi: 10.1016/S0031-9422(00)85672-1

Meyer, A., Cirpus, P., Ott, C., Schlecker, R., Zähringer, U., and Heinz, E. (2003). Biosynthesis of docosahexaenoic acid in Euglena gracilis: biochemical and molecular evidence for the involvement of a $\Delta 4$-fatty acyl group desaturase. Biochemistry 42, 9779-9788. doi: 10.1021/bi034731y

Milani, A., Basirnejad, M., Shahbazi, S., and Bolhassani, A. (2017). Carotenoids: biochemistry, pharmacology and treatment. Br. J. Pharmacol. 174, 1290-1324. doi: 10.1111/bph.13625

Miyatake, K., and Kitaoka, S. (1983). Comparison of the methods for determining degree of polymerization of water-insoluble $\beta$-1,3-glucans. Bull. Univ. Osaka Prefecture Ser. B Agricult. Biol. 35, 55-58.

Monfils, A.K., Triemer, R.E., and Bellairs, E.F. (2011). Characterization of paramylon morphological diversity in photosynthetic euglenoids (Euglenales, Euglenophyta). Phycologia 50, 156-169. doi: 10.2216/09-112.1

Müller, C., Ortmann, T., Abi, A., Hartig, D., Scholl, S., and Jördening, H.-J. (2016). Immobilization and characterization of E. gracilis extract with enriched laminaribiose phosphorylase activity for bienzymatic production of laminaribiose. Appl. Biochem. Biotechnol. 182, 197-215. doi: 10.1007/s12010-016-2320-4

Muñoz, H.E., Li, M., Riche, C.T., Nitta, N., Diebold, E., Lin, J., et al. (2018). Single-cell analysis of morphological and metabolic heterogeneity in Euglena gracilis by fluorescence-imaging flow cytometry. Anal. Chem. 90, 11280-11289. doi: 10.1021/acs.analchem.8b01794

Mussatto, S.I., Dragone, G., Guimarães, P.M.R., Silva, J.P.A., Carneiro, L.M., Roberto, I.C., et al. (2010). Technological trends, global market, and challenges of bio-ethanol production. Biotechnol. Adv. 28, 817-830. doi: 10.1016/j.biotechadv.2010.07.001

Nakashima, A., Sugimoto, R., Suzuki, K., Shirakata, Y., Hashiguchi, T., Yoshida, C., et al. (2018a). Anti-fibrotic activity of Euglena gracilis and paramylon in a mouse model of non-alcoholic steatohepatitis. Food Sci. Nutr. 7, 139-147. doi: $10.1002 /$ fsn 3.828

Nakashima, A., Suzuki, K., Asayama, Y., Konno, M., Saito, K., Yamazaki, N., et al. (2017). Oral administration of Euglena gracilis $Z$ and its carbohydrate storage substance provides survival protection against influenza virus infection in mice. Biochem. Biophys. Res. Commun. 494, 379-383. doi: 10.1016/j.bbrc.2017.09.167

Nakashima, A., Yamada, K., Iwata, O., Sugimoto, R., Atsuji, K., Ogawa, T., et al. (2018b). $\beta$-glucan in foods and its physiological functions. J. Nutr. Sci. Vitaminol. 64, 8-17. doi: 10.3177/jnsv.64.8
Nakazawa, M., Andoh, H., Koyama, K., Watanabe, Y., Nakai, T., Ueda, M., et al. (2015). Alteration of wax ester content and composition in Euglena gracilis with gene silencing of 3-ketoacyl-coa thiolase isozymes. Lipids 50, 483-492. doi: 10.1007/s11745-015-4010-3

Nandy, S.K., and Srivastava, R.K. (2018). A review on sustainable yeast biotechnological processes and applications. Microbiol. Res. 207, 83-90. doi: 10.1016/j.micres.2017.11.013

Niki, E., and Traber, M.G. (2012). A history of vitamin E. Ann. Nutr. Metabol. 61, 207-212. doi: 10.1159/000343106

Ntefidou, M., Iseki, M., Watanabe, M., Lebert, M., and Häder, D.-P. (2003). Photoactivated adenylyl cyclase controls phototaxis in the flagellate Euglena gracilis. Plant Physiol. 133, 1517-1521. doi: 10.1104/pp.103.034223

Ntefidou, M., Lüdtke, T., Ahmad, M., and Häder, D.-P. (2006). Heterologous expression of photoactivated adenylyl cyclase (PAC) genes from the flagellate Euglena gracilis in insect cells. Photochem. Photobiol. 82, 1601-1605. doi: 10.1111/j.1751-1097.2006.tb09818.x

Ogawa, T., Tamoi, M., Kimura, A., Mine, A., Sakuyama, H., Yoshida, E., et al. (2015). Enhancement of photosynthetic capacity in Euglena gracilis by expression of cyanobacterial fructose-1,6-/sedoheptulose-1,7-bisphosphatase leads to increases in biomass and wax ester production. Biotechnol. Biofuels 8, 80-91. doi: 10.1186/s13068-015-0264-5

Ogawa, Y., Noda, K., Kimura, S., Kitaoka, M., and Wada, M. (2014). Facile preparation of highly crystalline lamellae of $(1 \rightarrow 3)-\beta$-D-glucan using an extract of Euglena gracilis. Int. J. Biol. Macromol. 64, 415-419. doi: 10.1016/j.ijbiomac.2013.12.027

Ogbonna, J., Ichige, E., and Tanaka, H. (2002). Interactions between photoautotrophic and heterotrophic metabolism in photoheterotrophic cultures of Euglena gracilis. Appl. Microbiol. Biotechnol. 58, 532-538. doi: 10.1007/s00253-001-0901-8

Ogbonna, J.C., Tomiyamal, S., and Tanaka, H. (1998). Heterotrophic cultivation of Euglena gracilis Z for efficient production of $\alpha$-tocopherol. J. Appl. Phycol. 10, 67-74. doi: 10.1023/a:1008011201437

O’Neill, E.C., Trick, M., Henrissat, B., and Field, R.A. (2015a). Euglena in time: evolution, control of central metabolic processes and multi-domain proteins in carbohydrate and natural product biochemistry. Perspect. Sci. 6, 84-93. doi: 10.1016/j.pisc.2015.07.002

O’Neill, E.C., Trick, M., Hill, L., Rejzek, M., Dusi, R.G., Hamilton, C.J., et al. (2015b). The transcriptome of Euglena gracilis reveals unexpected metabolic capabilities for carbohydrate and natural product biochemistry. Mol. BioSyst. 11, 2808-2820. doi: 10.1039/C5MB00319A

Ooi, V.E., and Liu, F. (2000). Immunomodulation and anti-cancer activity of polysaccharide-protein complexes. Curr. Med. Chem. 7, 715-729. doi: 10.2174/0929867003374705

Papadaki, A., Mallouchos, A., Efthymiou, M.-N., Gardeli, C., Kopsahelis, N., Aguieiras, E.C.G., et al. (2017). Production of wax esters via microbial oil synthesis from food industry waste and by-product streams. Bioresource Technol. 245, 274-282. doi: 10.1016/j.biortech.2017.08.004

Plante, O.J., Palmacci, E.R., and Seeberger, P.H. (2001). Automated solid-phase synthesis of oligosaccharides. Science 291, 1523-1527. doi: 10.1126/science.1057324

Pollak, D.W., Bostick, M.W., Yoon, H., Wang, J., Hollerbach, D.H., He, H., et al. (2012). Isolation of a $\Delta 5$ desaturase gene from Euglena gracilis and functional dissection of its HPGG and HDASH motifs. Lipids 47, 913-926. doi: 10.1007/s11745-012-3690-1

Portnoy, V.A., Bezdan, D., and Zengler, K. (2011). Adaptive laboratory evolution - harnessing the power of biology for metabolic engineering. Curr. Opin. Biotechnol. 22, 590-594. doi: 10.1016/j.copbio.2011.03.007

Psomiadou, E., Tsimidou, M., and Boskou, D. (2000). $\alpha$-tocopherol content of greek virgin olive oils. J. Agricult. Food Chem. 48, 1770-1775. doi: 10.1021/jf990993o

Qi, B., Fraser, T., Mugford, S., Dobson, G., Sayanova, O., Butler, J., et al. (2004). Production of very long chain polyunsaturated omega-3 and omega-6 fatty acids in plants. Nat. Biotechnol. 22, 739-745. doi: 10.1038/nbt972

Ramazanov, A., and Ramazanov, Z. (2006). Isolation and characterization of a starchless mutant of Chlorella pyrenoidosa STL-PI with a high growth rate, and high protein and polyunsaturated fatty acid content. Phycol. Res. 54, 255-259. doi: $10.1111 /$ j.1440-1835.2006.00416.x 
Ramos, M.J., Fernández, C.M., Casas, A., Rodríguez, L., and Pérez, Á. (2009). Influence of fatty acid composition of raw materials on biodiesel properties. Bioresource Technol. 100, 261-268. doi: 10.1016/j.biortech.2008.06.039

Rice, P.J., Adams, E.L., Ozment-Skelton, T., Gonzalez, A.J., Goldman, M.P., Lockhart, B.E., et al. (2005). Oral delivery and gastrointestinal absorption of soluble glucans stimulate increased resistance to infectious challenge. J. Pharmacol. Exp. Therapeut. 314, 1079-1086. doi: 10.1124/jpet.105.085415

Richmond, A., Cheng-Wu, Z., and Zarmi, Y. (2003). Efficient use of strong light for high photosynthetic productivity: interrelationships between the optical path, the optimal population density and cell-growth inhibition. Biomol. Eng. 20, 229-236. doi: 10.1016/S1389-0344(03)00060-1

Rigotti, A. (2007). Absorption, transport, and tissue delivery of vitamin E. Mol. Aspects Med. 28, 423-436. doi: 10.1016/j.mam.2007.01.002

Ritala, A., Häkkinen, S.T., Toivari, M., and Wiebe, M.G. (2017). Single cell protein - state-of-the-art, industrial landscape and patents 2001-2016. Front. Microbiol. 8, 1-18. doi: 10.3389/fmicb.2017.02009

Rodríguez-Zavala, J.S., Ortiz-Cruz, M.A., Mendoza-Hernández, G., and MorenoSánchez, R. (2010). Increased synthesis of $\alpha$-tocopherol, paramylon and tyrosine by Euglena gracilis under conditions of high biomass production. J. Appl. Microbiol. 109, 2160-2172. doi: 10.1111/j.1365-2672.2010.04848.x

Rosenberg, A. (1963). A comparison of lipid patterns in photosynthesizing and nonphotosynthesizing cells of Euglena gracilis. Biochemistry 2, 1148-1154. doi: 10.1021/bi00905a042

Russo, R., Barsanti, L., Evangelista, V., Frassanito, A.M., Longo, V., Pucci, L., et al. (2017). Euglena gracilis paramylon activates human lymphocytes by upregulating pro-inflammatory factors. Food Sci. Nutr. 5, 205-214. doi: $10.1002 /$ fsn 3.383

Sakagami, H., Unten, S., Hanaoka, A., Ohsawa, N., Fujimaki, M., Komatsu, N., et al. (1989). Chemical modification potentiates paramylon induction of antimicrobial activity. In vivo 3, 243-247.

Šantek, B., Felski, M., Friehs, K., Lotz, M., and Flaschel, E. (2010). Production of paramylon, a $\beta$-1,3-glucan, by heterotrophic cultivation of Euglena gracilis on potato liquor. Eng. Life Sci. 10, 165-170. doi: 10.1002/elsc.2009 00077

Šantek, B., Friehs, K., Lotz, M., and Flaschel, E. (2012). Production of paramylon, a $\beta$-1,3-glucan, by heterotrophic growth of Euglena gracilis on potato liquor in fed-batch and repeated-batch mode of cultivation. Eng. Life Sci. 12, 89-94. doi: 10.1002/elsc.201100025

Santini, A., Cammarata, S.M., Capone, G., Ianaro, A., Tenore, G.C., Pani, L., et al. (2018). Nutraceuticals: opening the debate for a regulatory framework. Br. J. Clin. Pharmacol. 84, 659-672. doi: 10.1111/bcp.13496

Schiff, J.A., Lyman, H., and Russell, G.K. (1980). "Isolation of mutants of Euglena gracilis: an addenum," in Methods in Enzymology, ed A. San Pietro (Cambridge: Academic Press), 23-29.

Shibakami, M., Shibata, K., Akashi, A., Onaka, N., Takezaki, J., Tsubouchi, G., et al. (2018). Creation of straight-chain cationic polysaccharide-based bile salt sequestrants made from euglenoid $\beta$-1,3-glucan as potential antidiabetic agents. Pharmaceut. Res. 36, 1-11. doi: 10.1007/s11095-018-2553-8

Shibakami, M., and Sohma, M. (2018). Thermal, crystalline, and pressuresensitive adhesive properties of paramylon monoesters derived from an euglenoid polysaccharide. Carbohydrate Polymers 200, 239-247. doi: 10.1016/j.carbpol.2018.08.005

Shibakami, M., Tsubouchi, G., and Hayashi, M. (2014). Thermoplasticization of euglenoid $\beta$-1,3-glucans by mixed esterification. Carbohydrate Polymers 105, 90-96. doi: 10.1016/j.carbpol.2014.01.053

Shibakami, M., Tsubouchi, G., Nakamura, M., and Hayashi, M. (2013a). Polysaccharide nanofiber made from euglenoid alga. Carbohydrate Polymers 93, 499-505. doi: 10.1016/j.carbpol.2012.12.040

Shibakami, M., Tsubouchi, G., Nakamura, M., and Hayashi, M. (2013b). Preparation of carboxylic acid-bearing polysaccharide nanofiber made from euglenoid $\beta$-1,3-glucans. Carbohydrate Polymers 98, 95-101. doi: 10.1016/j.carbpol.2013.05.026

Shigeoka, S., Ishiko, H., Nakano, Y., and Mitsunaga, T. (1992). Isolation and properties of $\gamma$-tocopherol methyltransferase in Euglena gracilis. Biochim. Biophys. Acta (BBA) Lipids Lipid Metab. 1128, 220-226. doi: 10.1016/0005-2760(92)90311-I
Shigeoka, S., Nakano, Y., and Kitaoka, S. (1979). The biosynthetic pathway of L-ascorbic acid in Euglena gracilis Z. J. Nutr. Sci. Vitaminol. 25, 299-307. doi: $10.3177 /$ jnsv.25.299

Shigeoka, S., Nakano, Y., and Kitaoka, S. (1980). Occurrence of L-ascorbic acid in Euglena gracilis Z. Bull. Univ. Osaka Prefecture Ser. B Agricult. Biol. 32, 43-48.

Shigeoka, S., Onishi, T., Nakano, Y., and Kitaoka, S. (1986). The contents and subcellular distribution of tocopherols in Euglena gracilis. Agricult. Biol. Chem. 50, 1063-1065. doi: 10.1080/00021369.1986.10867518

Shigeoka, S., Toshio, O., Yoshihisa, N., and Shozaburo, K. (1987). Requirement for vitamin $\mathrm{B}_{1}$ for growth of Euglena gracilis. Microbiology 133, 25-30. doi: 10.1099/00221287-133-1-25

Shimada, I., Nakamura, Y., Kato, S., Mori, R., Ohta, H., Suzuki, K., et al. (2018). Catalytic cracking of wax esters extracted from Euglena gracilis for hydrocarbon fuel production. Biomass Bioenergy 112, 138-143. doi: 10.1016/j.biombioe.2018.03.004

Skov, J., Kania, P.W., Holten-Andersen, L., Fouz, B., and Buchmann, K. (2012). Immunomodulatory effects of dietary $\beta$-1,3-glucan from Euglena gracilis in rainbow trout (Oncorhynchus mykiss) immersion vaccinated against Yersinia ruckeri. Fish Shellfish Immunol. 33, 111-120. doi: 10.1016/j.fsi.2012.04.009

Sonck, E., Stuyven, E., Goddeeris, B., and Cox, E. (2010). The effect of $\beta$ glucans on porcine leukocytes. Vet. Immunol. Immunopathol. 135, 199-207. doi: 10.1016/j.vetimm.2009.11.014

Sugiyama, A., Hata, S., Suzuki, K., Yoshida, E., Nakano, R., Mitra, S., et al. (2010). Oral administration of paramylon, a $\beta$-1,3-D-glucan isolated from Euglena gracilis $\mathrm{Z}$ inhibits development of atopic dermatitis-like skin lesions in NC/Nga mice. J. Vet. Med. Sci. 72, 755-763. doi: 10.1292/jvms.09-0526

Sugiyama, A., Suzuki, K., Mitra, S., Arashida, R., Yoshida, E., Nakano, R., et al. (2009). Hepatoprotective effects of paramylon, a $\beta-1,3-\mathrm{D}$-glucan isolated from Euglena gracilis Z, on acute liver injury induced by carbon tetrachloride in rats. J. Vet. Med. Sci. 71, 885-890. doi: 10.1292/jvms.71.885

Sumida, S., Ehara, T., Osafune, T., and Hase, E. (1987). Ammonia- and lightinduced degradation of paramylum in Euglena gracilis. Plant Cell Physiol. 28, 1587-1592. doi: 10.1093/oxfordjournals.pcp.a077454

Sun, A., Hasan, M.T., Hobba, G., Nevalainen, H., and Te'o, J. (2018). Comparative assessment of the Euglena gracilis var. saccharophila variant strain as a producer of the $\beta$-1,3-glucan paramylon under varying light conditions. J. Phycol. 54, 529-538. doi: 10.1111/jpy.12758

Sutivisedsak, N., Leathers, T.D., Bischoff, K.M., Nunnally, M.S., and Peterson, S.W. (2013). Novel sources of $\beta$-glucanase for the enzymatic degradation of schizophyllan. Enzyme Microb. Technol. 52, 203-210. doi: 10.1016/j.enzmictec.2012.12.002

Suzuki, K. (2017). "Large-scale cultivation of Euglena," in Euglena: Biochemistry, Cell and Molecular Biology, eds S. D. Schwartzbach and S. Shigeoka (Cham: Springer International Publishing), 285-293.

Suzuki, K., Nakashima, A., Igarashi, M., Saito, K., Konno, M., Yamazaki, N., et al. (2018). Euglena gracilis $\mathrm{Z}$ and its carbohydrate storage substance relieve arthritis symptoms by modulating Th17 immunity. PLoS ONE 13, 1-14. doi: 10.1371/journal.pone.0191462

Takeda, T., Nakano, Y., Takahashi, M., Konno, N., Sakamoto, Y., Arashida, R., et al. (2015). Identification and enzymatic characterization of an endo-1,3- $\beta$-glucanase from Euglena gracilis. Phytochemistry 116, 21-27. doi: $10.1016 /$ j.phytochem.2015.05.010

Takeyama, H., Kanamaru, A., Yoshino, Y., Kakuta, H., Kawamura, Y., and Matsunaga, T. (1997). Production of antioxidant vitamins, $\beta$-carotene, vitamin $\mathrm{C}$, and vitamin $\mathrm{E}$, by two-step culture of Euglena gracilis Z. Biotechnol. Bioeng. 53, 185-190. doi: 10.1002/(SICI)1097-0290(19970120)53:2<185::AID-BIT8>3.0.CO;2-K

Tanaka, Y., Ogawa, T., Maruta, T., Yoshida, Y., Arakawa, K., and Ishikawa, T. (2017). Glucan synthase-like 2 is indispensable for paramylon synthesis in Euglena gracilis. FEBS Lett. 591, 1360-1370. doi: 10.1002/1873-3468.12659

Tandon, P., Jin, Q., and Huang, L. (2017). A promising approach to enhance microalgae productivity by exogenous supply of vitamins. Microb. Cell Factories 16, 1-13. doi: 10.1186/s12934-017-0834-2

Teerawanichpan, P., and Qiu, X. (2010). Fatty acyl-CoA reductase and wax synthase from Euglena gracilis in the biosynthesis of medium-chain wax esters. Lipids 45, 263-273. doi: 10.1007/s11745-010-3395-2 
Tokuşoglu, Ö., and Ünal, M.K. (2003). Biomass nutrient profiles of three microalgae: Spirulina platensis, Chlorella vulgaris, and Isochrisis galbana. J. Food Sci. 68, 1144-1148. doi: 10.1111/j.1365-2621.2003.tb09615.x

Tomiyama, T., Kurihara, K., Ogawa, T., Maruta, T., Ogawa, T., Ohta, D., et al. (2017). Wax ester synthase/diacylglycerol acyltransferase isoenzymes play a pivotal role in wax ester biosynthesis in Euglena gracilis. Sci. Rep. 7, 1-13. doi: 10.1038/s41598-017-14077-6

Torihara, K., and Kishimoto, N. (2015). Evaluation of growth characteristics of Euglena gracilis for microalgal biomass production using wastewater. J. Water Environ. Technol. 13, 195-205. doi: 10.2965/jwet.2015.195

Tossavainen, M., Katyal Chopra, N., Kostia, S., Valkonen, K., Sharma, A.K., Sharma, S., et al. (2018). Conversion of biowaste leachate to valuable biomass and lipids in mixed cultures of Euglena gracilis and chlorophytes. Algal Res. 35, 76-84. doi: 10.1016/j.algal.2018.08.007

Traber, M.G. (2014). Vitamin E inadequacy in humans: causes and consequences. Adv. Nutr. 5, 503-514. doi: 10.3945/an.114.006254

Tucci, S., Vacula, R., Krajcovic, J., Proksch, P., and Martin, W. (2010). Variability of wax ester fermentation in natural and bleached Euglena gracilis strains in response to oxygen and the elongase inhibitor flufenacet. J. Eukaryot. Microbiol. 57, 63-69. doi: 10.1111/j.1550-7408.2009.00452.x

US Department of Agriculture. (2018). USDA National Nutrient Database for Standard Reference.

Vogel, K., and Barber, A.A. (1968). Degradation of paramylon by Euglena gracilis. J. Protozool. 15, 657-662. doi: 10.1111/j.1550-7408.1968.tb02189.x

Wallis, J.G., and Browse, J. (1999). The $\Delta 8$-desaturase of Euglena gracilis: an alternate pathway for synthesis of 20-carbon polyunsaturated fatty acids. Arch. Biochem. Biophys. 365, 307-316. doi: 10.1006/abbi.1999.1167

Wang, Y., Seppänen-Laakso, T., Rischer, H., and Wiebe, M.G. (2018). Euglena gracilis growth and cell composition under different temperature, light and trophic conditions. PLoS ONE 13, 1-17. doi: 10.1371/journal.pone.0195329

Watanabe, T., Shimada, R., Matsuyama, A., Yuasa, M., Sawamura, H., Yoshida, E., et al. (2013). Antitumor activity of the $\beta$-glucan paramylon from Euglena against preneoplastic colonic aberrant crypt foci in mice. Food Funct. 4, 1685-1690. doi: 10.1039/C3FO60256G

Weber, D., and Grune, T. (2012). The contribution of $\beta$-carotene to vitamin A supply of humans. Mol. Nutr. Food Res. 56, 251-258. doi: $10.1002 / \mathrm{mnfr} .201100230$

Williams, R.R., and Cline, J.K. (1936). Synthesis of vitamin B . J. Am. Chem. Soc. 58, 1504-1505. doi: 10.1021/ja01299a505

Wiseman, E.M., Bar-El Dadon, S., and Reifen, R. (2017). The vicious cycle of vitamin a deficiency: a review. Crit. Rev. Food Sci. Nutr. 57, 3703-3714. doi: 10.1080/10408398.2016.1160362

Yadavalli, R., Rao, C.S., Rao, R.S., and Potumarthi, R. (2014). Dairy effluent treatmentand lipids production by Chlorella pyrenoidosa and Euglena gracilis: study on open and closed systems. Asia-Pacific J. Chem. Eng. 9, 368-373. doi: 10.1002/apj.1805

Yamada, K., Suzuki, H., Takeuchi, T., Kazama, Y., Mitra, S., Abe, T., et al. (2016). Efficient selective breeding of live oil-rich Euglena gracilis with fluorescenceactivated cell sorting. Sci. Rep. 6, 1-8. doi: 10.1038/srep26327

Yamamoto, F.Y., Sutili, F.J., Hume, M., and Gatlin, D.M. (2018a). The effect of $\beta$-1,3-glucan derived from Euglena gracilis (Algamune ${ }^{\mathrm{TM}}$ ) on the innate immunological responses of Nile tilapia (Oreochromis niloticus L.). J. Fish Dis. 41, 1579-1588. doi: 10.1111/jfd.12871

Yamamoto, F.Y., Yin, F., Rossi Jr, W., Hume, M., and Gatlin Iii, D.M. (2018b). $\beta$-1,3 glucan derived from Euglena gracilis and Algamune enhances innate immune responses of red drum (Sciaenops ocellatus L.). Fish Shellfish Immunol. 77, 273-279. doi: 10.1016/j.fsi.2018.04.003

Yamane, Y.-,I., Utsunomiya, T., Watanabe, M., and Sasaki, K. (2001). Biomass production in mixotrophic culture of Euglena gracilis under acidic condition and its growth energetics. Biotechnol. Lett. 23, 1223-1228. doi: 10.1023/A:1010573218863

Yasuda, K., Ogushi, M., Nakashima, A., Nakano, Y., and Suzuki, K. (2018). Accelerated wound healing on the skin using a film dressing with $\beta$-glucan paramylon. In Vivo 32, 799-805. doi: 10.21873/invivo.11310

Yoshida, Y., Tomiyama, T., Maruta, T., Tomita, M., Ishikawa, T., and Arakawa, K. (2016). De novo assembly and comparative transcriptome analysis of Euglena gracilis in response to anaerobic conditions. BMC Genomics 17, 1-10. doi: 10.1186/s12864-016-2540-6

Yu, L., Wu, J.-R., Liu, J., Zhan, X., Zheng, Z., and Lin, C.-C. (2011). Enhanced curdlan production in Agrobacterium sp. ATCC 31749 by addition of low-polyphosphates. Biotechnol. Bioprocess Eng. 16, 34-41. doi: 10.1007/s12257-010-0145-5

Zhu, G., Ou, Q., Zhang, T., Jiang, X., Sun, G., Zhang, N., et al. (2014). A more desirable balanced polyunsaturated fatty acid composition achieved by heterologous expression of $\Delta 15 / \Delta 4$ desaturases in mammalian cells. PLoS ONE 8, 1-6. doi: 10.1371/journal.pone.0084871

Conflict of Interest Statement: The authors declare that the research was conducted in the absence of any commercial or financial relationships that could be construed as a potential conflict of interest.

Copyright (C) 2019 Gissibl, Sun, Care, Nevalainen and Sunna. This is an open-access article distributed under the terms of the Creative Commons Attribution License (CC $B Y)$. The use, distribution or reproduction in other forums is permitted, provided the original author(s) and the copyright owner(s) are credited and that the original publication in this journal is cited, in accordance with accepted academic practice. No use, distribution or reproduction is permitted which does not comply with these terms. 